\title{
El reto del laicado en el marco de una eclesiología total: misión, comunión, formación
}

\author{
The Challenge of the Laity within the Framework of a \\ Total Ecclesiology: Mission, Communion, Formation
}

\author{
Francisco A. Castro Pérez \\ Profesor del CSET "San Pablo" (Málaga) \\ Delegado de Apostolado Seglar de la Diócesis de Málaga \\ francisco.castroperez@diocesismalaga.es
}

\begin{abstract}
Resumen: Este artículo describe el reto que el protagonismo laical supone en los campos, inseparables y mutuamente referidos, de la misión, la comunión y la formación. La "teología del laicado", en el orden teórico, y el apostolado seglar, en el práctico, se contemplan en el horizonte de una "eclesiología total" (Congar). La realidad de un "Pueblo de Dios en salida" solo será concretamente posible a través de la corresponsabilidad y la complementariedad de fieles y pastores.
\end{abstract}

Palabras claves: apostolado seglar, carismas, evangelización, sinodalidad
Abstract: This paper describes the challenge posed by lay protagonism in the inseparable and mutually referred fields of mission, communion and formation. "Theology of Laity", on the theoretical side, and lay apostolate, on the practical side, are dealt with in the light of a "total ecclesiology" (Congar). The reality of a "People of God which goes forth" will be concretely possible only through the coresponsibility and complementarity of the lay faithful and pastors.

Keywords: lay apostolate, charisms, evangelisation, sinodality

La Asamblea del Sínodo de los Obispos dedicada a"la nueva evangelización para la transmisión de la fe cristiana" (2012) y la sucesiva Exhortación apostólica del Papa Francisco Evangelii gaudium han ayudado a que todo el Pueblo de Dios vaya asumiendo con nuevo ardor el desafío de la evangelización en nuestro tiempo. ${ }^{1}$ Todos en la Iglesia somos convocados a

1 Cf. SínOdo de los OBISPos, XIII Asamblea general ordinaria. La nueva evangelización para la transmisión de la fe cristiana. Instrumentum laboris, Ciudad del Vaticano, Secretaría General del Sínodo - Libreria Editrice Vaticana, 2012; FRANCISCO, Exhortación apostólica Evangelii gaudium (EG) sobre el anuncio el Evangelio en el mundo actual, AAS 105 (2013) 1019-1137. 
un proceso de "discernimiento, purificación y reforma", ${ }^{2}$ que estimule y dé cauce a un caminar conjunto del Pueblo de Dios, donde fieles y pastores según su vocación y función propias puedan colaborar en la transformación misionera de la vida y las estructuras eclesiales. La convocatoria, por parte de la Conferencia Episcopal Española, de un Congreso nacional "de Laicos" (febrero de 2020), ha de interpretarse, precisamente, en este contexto. ${ }^{3}$

En todo esto puede percibirse la llamada que el Espíritu del Señor está haciendo a su Iglesia, sobre todo a partir del Concilio Vaticano II, para afrontar el desafío de la"nueva etapa evangelizadora" que se abre ante nosotros. ${ }^{4}$ En esta etapa, es de esperar un creciente protagonismo de los laicos, de acuerdo con la conciencia que paulatinamente se ha ido ganando en la Iglesia acerca de la común dignidad y vocación a la santidad de todos los bautizados, así como de las irrenunciables dimensiones comunitaria y apostólica de toda vida cristiana. En estas páginas, describimos el reto que este protagonismo laical supone en los campos, inseparables y mutuamente referidos, de la misión, la comunión y la formación.

Asimismo, pretendemos ensanchar la perspectiva, apuntando a la necesaria superación de una "teología del laicado" que no tenga como horizonte una "eclesiología total", tal como señaló en su tiempo Congar y quedó sancionado por los documentos conciliares. ${ }^{5}$ Una acogida más honda de aquellas reflexiones puede iluminar también hoy una praxis eclesial donde la corresponsabilidad y la complementariedad de fieles y pastores haga concretamente posible la realidad de un"Pueblo de Dios en salida".

\section{LA CONSTITUCIÓN DE UN “LAICADO MADURO”}

Los fieles laicos han sido considerados durante un largo tiempo como sujetos solo pasivos y en permanente minoría de edad (Ecclesia discens), en una Iglesia concebida como sociedad de desiguales. ${ }^{6}$ Frente a esto,

\footnotetext{
2 EG 31.

3 C. Conferencia Episcopal Española (CVI Asamblea Plenaria), Iglesia en misión al servicio de nuestro pueblo. Plan pastoral 2016-2020, Madrid, Edice, 2015, 49; Comisión EpISCOPAL de Apostolado Seglar, Un laicado en acción. Vivir el sueño misionero de llegar a todas las personas. Instrumento de trabajo para la preparación del Congreso Nacional de Laicos, Madrid, Edice, 2020; Pueblo de Dios en salida. Ponencias del Congreso Nacional de Laicos, Ecclesia 4021 (encarte, 14-16 de febrero de 2020); Delegación de Apostolado Seglar, Caminar unidos después del Congreso de Laicos, Málaga, Diócesis de Málaga, 2020.

4 EG 1.

5 "En el fondo sólo hay una teología del laicado válida: una eclesiología total": Yves Congar, Jalones para una teología del laicado, Barcelona, Estela, ${ }^{3} 1965,13$.

6 Así aparecía, como es conocido, en el esquema De Ecclesia del Concilio Vaticano I que no llegó a promulgarse. Cf. Schema de Ecclesia Christi, en Giovanni Domenico MansI,
} 
el último Concilio recoge en un capítulo específico la experiencia y la reflexión de los decenios anteriores, que dieron lugar a una fecunda"teología del laicado". ${ }^{7}$ Los fieles laicos dejan de ser caracterizados solo en forma negativa, como los que no son ni clérigos ni monjes, para ser, en cambio, comprendidos su lugar y misión en la Iglesia y en el mundo sobre la base de una teología bautismal.

Son pues, los cristianos que están incorporados a Cristo por el bautismo, que forman el Pueblo de Dios y que participan de las funciones de Cristo: Sacerdote, Profeta y Rey. Ellos realizan, según su condición, la misión de todo el pueblo cristiano en la Iglesia y en el mundo. ${ }^{8}$

\subsection{Miembros de un mismo Pueblo}

Esto se hace, además, colocando la noción de"Pueblo de Dios" en el centro de la comprensión que la Iglesia tiene de sí misma..$^{9}$ Esto supone un "giro copernicano", que nos reclama superar la inercia de una noción clerical de la Iglesia. En la base, se encuentra el redescubrimiento de los sacramentos de la iniciación cristiana como fundamento de la vida y la misión de toda la Iglesia y de cada uno de los cristianos, de lo cual surge una concepción eclesial más comunional y eucarística.

El capítulo segundo nos da una visión de la Iglesia dinámica, histórica, concreta, escatológica: la comunidad fraternal de los creyentes ocupa el primer plano. Esta comunidad, jerárquicamente estructurada sin duda, aparece ante todo como comunidad sacramental fundada en el bautismo y en la eucaristía: una eclesiología de comunión. ${ }^{10}$

Sacrorum Conciliorum nova et amplissima collectio, t. 51 (Sacrosanctum oecumenicum concilium Vaticanum. Pars secunda. Acta synodalia), Arnhem - Leipzig, Société nouvelle d'édition de la Collection Mansi (H. Welter), 1926, col. 539-636. "Christi autem ecclesia non est societas aequalium, ac si omnes in ea fideles eadem iura haberent; verum est societas innequalis, et hoc non ideo tantum, quia fidelium alii clerici sunt, alii laici; sed propterea maxime, quod in ecclesia est potestas divinitus instituta, qua alii ad sanctificandum, docendum et regendum praediti sunt, alii destituuntur." Ibid., col. 543.

7 Cf. LG 30-38 (capítulo IV de la Constitución sobre la Iglesia Lumen gentium); CEC 897913. Cf. Gérard Philips, La Iglesia y su misterio en el Concilio Vaticano II. Historia, texto y comentario de la constitución "Lumen Gentium", vol. 2, Barcelona, Herder, 1969, 13-85.

8 LG 31. Acerca de esta consideración positiva del laicado, en equilibrio entre las exageraciones históricas de los polos jerárquico y comunitario en la Iglesia, cf. CONGAR, Jalones, 21-76.

9 Cf. LG 9-17 (capítulo II).

10 Card. Leo Joseph SuEnEns, "Algunas tareas teológicas de la hora actual", Concilium 60 (número extra, diciembre 1970), 183-193; aquí, pp. 185-186. Fue Suenens quien calificó de"revolución copernicana"la estructuración de los contenidos eclesiológicos en Lumen gentium (p. 185). Acerca de la trascendencia de colocar el capítulo II de Lumen gentium 
De una conciencia cada vez mayor de esta realidad depende la revitalización del apostolado seglar que esperamos en nuestro tiempo. Ya el Decreto conciliar Ad gentes sobre la acción misionera de la Iglesia señalaba la participación estable de los laicos en la evangelización como elemento esencial y signo inequívoco de una plantatio Ecclesiae lograda. Merece la pena recordar y tomar nota de esta convicción, que no solo afecta a las Iglesias de reciente fundación:

La Iglesia no está verdaderamente fundada, ni vive plenamente, ni es un signo perfecto de Cristo entre los hombres, mientras no exista y trabaje con la jerarquía un laicado propiamente dicho. Porque el evangelio no puede quedar profundamente grabado en las mentes, la vida y el trabajo de un pueblo sin la presencia activa de los laicos. Por ello, ya desde la fundación de la Iglesia se ha de atender sobre todo a la constitución de un laicado cristiano maduro. ${ }^{11}$

De este modo se verifica, en la dimensión decisiva de la evangelización, la complementariedad que los mismos textos conciliares señalan acerca del sacerdocio común y el ministerio ordenado. ${ }^{12}$ La impregnación de los valores del evangelio en un pueblo no puede realizarse sin la acción de los fieles laicos.

\subsection{El despertar del laicado}

El apostolado de los laicos, definido por el Concilio Vaticano II como "una participación en la misión salvadora misma de la Iglesia", ${ }^{13}$ constituye una dimensión esencial e irrenunciable de la vida de cada cristiano; pues"la vocación cristiana, por su misma naturaleza, es también vocación al apostolado".${ }^{14} \mathrm{La}$ voz del papa Francisco ha insistido en esta

en su orden, puede leerse también Santiago MADRIGAL, Unas lecciones sobre el Vaticano II y su legado, Madrid, San Pablo - Universidad Pontificia Comillas, 2012, 213-223.

11 AG 21.

12 Cf. LG 10; 33; 37; AA 3. Esta relación complementaria manifiesta en el sacerdocio de los fieles, el papel activo de los laicos, el sensus fidelium, la trama comunitaria y el apostolado es uno de los hilos conductores de CongAR, Jalones. Respigando los textos conciliares, destaca esta complementariedad, como fundamento de una constitutiva sinodalidad eclesial, Dario VITALI, "El Sínodo de los obispos al servicio de una Iglesia sinodal: los sujetos de la sinodalidad a la luz de la eclesiología del Vaticano II", Mater Clementissima 1 (2016) 7-57. Respecto a la vida consagrada, no puede hablarse de complementariedad en el mismo sentido, pues no pertenece a la estructura de la Iglesia, sino"a su vida y a su santidad" (LG 44):"no es un estado intermedio entre el clero y los laicos. Más bien Dios llama a algunos cristianos de ambos estados a gozar de un don particular en la vida de la Iglesia y a contribuir, cada uno a su manera, a la misión salvadora de ésta" (LG 43).

13 LG 33

14 AA 2. 
dimensión, por la cual el entero Pueblo de Dios es el sujeto de la misión evangelizadora y cada bautizado está llamado a desplegar su vocación de "discípulo misionero". En el párrafo 102 de su exhortación Evangelii gaudium, referido al apostolado seglar, se dan algunas orientaciones para el fortalecimiento de esta realidad.

En primer lugar, de las afirmaciones del Papa se desprende que el apostolado de los laicos es una realidad teológica y doctrinalmente fundada: "Los laicos son simplemente la inmensa mayoría del Pueblo de Dios. A su servicio está la minoría de los ministros ordenados." Detrás de esta afirmación, aparentemente superflua, late la doctrina del Concilio que afirma la común dignidad y vocación de todos los miembros de la Iglesia - expresada en la prioridad de la categoría "Pueblo de Dios" respecto a su constitución jerárquica- y la condición ministerial del sacerdocio ordenado - el cual está al servicio del desarrollo del sacerdocio común de los fieles-.${ }^{15}$ El Concilio consagró así la experiencia y la teología del laicado que se había ido gestando en los decenios anteriores, al mismo tiempo que la englobó en una visión más amplia y renovada de toda la Iglesia, a través de la fidelidad a sus propias raíces. Como Congar ya había advertido, se hizo necesario el marco de una "eclesiología total", donde las perspectivas parciales quedaran superadas y redimensionadas. ${ }^{16}$

La reflexión conciliar sucedió al despertar del laicado, como fenómeno históricamente acaecido en el pasado siglo, y que ha tenido un desarrollo inédito en los años postconciliares. Así lo certifica el papa Francisco en el mismo número de su exhortación:

Ha crecido la conciencia de la identidad y la misión del laico en la Iglesia. Se cuenta con un numeroso laicado, aunque no suficiente, con arraigado sentido de comunidad y una gran fidelidad en el compromiso de la caridad, la catequesis, la celebración de la fe. ${ }^{17}$

15 Cf. LG 10, 32 y la precedencia del capítulo II, sobre el Pueblo de Dios, respecto al capítulo dedicado a la jerarquía (capítulo III).

16 Cf. Congar, Jalones, 13. Esa eclesiología que encuadra la identidad y la misión del laicado la vemos expresada en los diversos documentos del Concilio, especialmente en los capítulos que preceden y siguen al dedicado específicamente a los laicos en Lumen Gentium (capítulo IV, nn. 30-38), en la Constitución pastoral Gaudium et spes sobre la Iglesia en el mundo actual y en el Decreto Apostolicam actuositatem sobre el apostolado de los laicos. No es este el lugar para exponer el panorama de reflexión teológica y de magisterio sobre el laicado que se desarrolla tras el Concilio, en el marco de una eclesiología renovada. Puede consultarse al respecto el estudio que, incluyendo la bibliografía más relevante, ofrece Santiago MADrigaL, El giro eclesiológico en la recepción del Vaticano II, Santander, Sal Terrae, 2017, 160-180.

17 EG 102. 
Como describió Guardini, en nuestro tiempo hemos recibido el don del"despertar de la Iglesia en las almas", por el cual muchos bautizados han accedido a una experiencia concreta, personal y comunitaria, de ser Iglesia, el Pueblo de Dios. ${ }^{18}$ Este despertar del laicado, sin embargo, ha sufrido cierto retroceso. Así diagnostica Francisco:

En algunos casos porque no se formaron para asumir responsabilidades importantes, en otros por no encontrar espacio en sus Iglesias particulares para poder expresarse y actuar, a raíz de un excesivo clericalismo que los mantiene al margen de las decisiones. [...] La formación de laicos y la evangelización de los grupos profesionales e intelectuales constituyen un desafío pastoral importante. ${ }^{19}$

El principal factor de parálisis no se encuentra en la dificultad de la evangelización, sino en el interior de la misma Iglesia. Se señala, en primer lugar, la enfermedad del clericalismo, que confunde la responsabilidad de evangelizar con la ocupación de espacios organizativos, en clave de influencia y poder. En segundo lugar, una formación deficiente del laicado. A este diagnóstico habría que añadir la larga lista de "tentaciones de los agentes pastorales", de los que se nos invita a examinarnos en EG 76-109, para terminar de salir de la perplejidad ante una"hora del laicado" que se marca en un "reloj parado".$^{20}$

\subsection{El reto eclesial del apostolado seglar}

Así pues, el despertar del laicado en la Iglesia, que es un don, se manifiesta también como un reto de conversión eclesial. En una Iglesia entendida como ámbito de los"profesionales" de lo religioso, ¿qué posición han de adoptar los laicos? Nos refería Congar: ¿sentados escuchando?, ¿de rodillas adorando?, ¿con la mano en el bolsillo para los donativos? ${ }^{21}$ Su posición propia es la de evangelizar en medio de la sociedad. En función de esto hay que entender la llamada a una conversión pastoral, a una transformación misionera de la Iglesia. Antes que en los planes pastorales, esta transformación ha de llegar a ser real en las actitudes de los cristianos. Si el compromiso de los cristianos despiertos está más inclinado a ver cómo subir al ambón que en cómo bajar a servir a los hermanos y a ser testigos, no estaríamos avanzando mucho.

\footnotetext{
18 Romano Guardini, Sentido de la Iglesia, San Sebastián, Dinor, 1958, 23-44.

19 EG 102.

20 Cf. Francisco, Carta al Cardenal Marc Ouellet, Presidente de la Pontificia Comisión para América Latina (19 de marzo de 2016), AAS 108 (2016) 525-530. Cf. AA 33.

21 Cf. Congar, Jalones, 7.
} 
En la perspectiva del apostolado, el reto que se nos plantea se concreta pastoralmente en la conjugación de tres dimensiones inseparables en la vivencia de la fe, entendida en la clave dinámica y misionera de comunicación de la fe. Siguiendo un análisis semiológico sencillo, podemos designar esas dimensiones constitutivas de una fe comunicable del siguiente modo: ${ }^{22}$

- Podemos designar como dimensión testimonial el quid (qué) de una fe capaz de ser comunicada, por la mediación de la presencia, de la diaconía eclesial hacia los pobres y sufrientes y del anuncio explícito. La fe, por esta dimensión, se hace propuesta concreta de sentido en la misión de la Iglesia.

- La dimensión mistagógica muestra el quomodo (cómo), la manera y el estilo eclesial de la acogida, del acompañamiento y de la ayuda entre los miembros de la comunidad. La fe, por esta dimensión, se manifiesta como comunión capaz de engendrar comunión, con el auxilio de la gracia y con el soporte de las mediaciones estructurales de la Iglesia (Palabra, sacramentos, ministerio).

- La dimensión dialógica manifiesta la importancia primordial del quis (quién), la formación y la disposición del cristiano como testigo capaz de una propuesta razonable de la fe. En ello se juega la constitución de un sujeto eclesial (a nivel tanto personal como comunitario), capaz de comunicar la fe de modo creíble.

Estas tres dimensiones hacen que la responsabilidad de constituir un laicado maduro deba incidir sobre la audacia de la misión, la fortaleza de la comunión y la solidez de la formación. Entre estas tres dimensiones existe una relación circular: si falla una, se resienten todas; fortalecer una hace ganar en autenticidad y fuerza a las demás. En esto se juega la vitalidad del apostolado seglar y, por ende, de la entera misión evangelizadora de la Iglesia.

\section{DINAMISMO INTEGRADOR DE LA MISIÓN}

La Iglesia existe para evangelizar. ${ }^{23}$ En este sentido, puede afirmarse una cierta prioridad de la misión respecto a las demás dimensiones. En torno a su "dinamismo integrador" cobran sentido todos los demás aspectos de cualquier proyecto formativo o de espiritualidad cristiana.

Formen: ofreciendo un proceso de crecimiento en la fe, un itinerario catequístico permanente orientado a la misión, adecuado a cada realidad, apoyados en la Palabra de Dios, para animar una feliz amistad con Jesús y la experiencia

22 Cf. Karl BüHLER, Teoría del lenguaje, Madrid, Revista de occidente, ${ }^{3} 1967,69-72$.

23 Cf. PABLOVI, Exhortación apostólica Evangelii nuntiandi (EN) sobre la evangelización en el mundo contemporáneo, AAS 68 (1976) 5-76, n. 14. 
de amor fraterno. Recen: en esa santa extroversión que pone el corazón en las necesidades del pueblo, en sus angustias, en sus alegrías. Una oración que camine, que los lleve bien lejos. Así evitarán estar mirándose continuamente a sí mismos. Sacrifíquense: pero no para sentirse más pulcros, sacrificio generoso es el que hace bien a los otros. Ofrezcan su tiempo buscando cómo hacer para que los otros crezcan, ofrezcan lo que hay en los bolsillos compartiendo con los que menos tienen, ofrezcan sacrificadamente el don de la vocación personal para embellecer y hacer crecer la casa común. ${ }^{24}$

\subsection{Un laicado en salida misionera}

La misión requiere audacia, en un tiempo en el que la Iglesia está embarcada en un proyecto de "nueva evangelización". ${ }^{25}$ Esto se muestra en el tono de urgencia que el Papa da a su llamada a"salir". Es precisa una salida de nosotros mismos, de nuestras costumbres, de nuestras comodidades, de nuestras certezas normativas..., con una mayor compasión por quienes carecen del tesoro de Jesucristo. Es preferible una Iglesia"herida" antes que rancia por estar encerrada en sus esquemas. ${ }^{26}$ Que se nos llame a salir, sin embargo, no puede hacernos olvidar que, en sentido propio, los cristianos ya estamos "fuera". La intercesión de Jesús por los suyos no es para retirarlos del mundo, al cual no pertenecen ya, sino para librarlos del mal en su modo propio de estar en el mundo testimonialmente. ${ }^{27}$ Precisamente, la "vocación propia" de los laicos corresponde a su"índole secular". ${ }^{28}$ Que los laicos estén ya en el corazón de la sociedad es la garantía de una evangelización capilar que solo por ellos se puede llevar a cabo, a nivel personal, en los distintos ambientes y también a nivel asociativo e institucional. ${ }^{29}$

En cualquier caso, la metafórica salida a la que somos llamados, ¿hacia dónde se dirige? Si se entiende como la ocupación de espacios eclesiales, una mayor implantación en parroquias de proyectos particulares de espiritualidad, formación o acción apostólica..., entonces no habremos salido en absoluto del esquema de cristiandad, ni se manifestaría una verdadera transformación misionera. La necesidad de evangelización apunta claramente a los ámbitos sociales e institucionales: los diversos rostros de la pobreza y del sufrimiento, la cultura, los ámbitos profesionales, la educación,

24 Francisco, Discurso a los participantes en el Congreso del Foro Internacional de la Acción Católica (27 de abril de 2017), AAS 109 (2017) 467-472.

25 Cf. Juan Pablo II, Encíclica Redemptoris missio (RM) sobre la permanente validez del mandato misionero, AAS 83 (1991) 249-340, n. 33.

26 EG 49. Cf. EG 20-24; 27; 30; 46; 97; 179; 261.

27 Cf. Jn 17,15-18.

28 LG 31.

29 Cf. Conferencia Episcopal Española, Los católicos en la vida pública (1986). 
los medios de comunicación, la cosa pública... Especialmente nos debe preocupar que los pobres (excluidos, sufrientes, débiles, necesitados...) no sean evangelizados, siendo esto el mayor signo del Reino. ${ }^{30}$ Debemos preguntarnos por qué para muchos que acuden a Cáritas, nuestras parroquias siguen siendo "la Iglesia de los ricos", en la que no se sienten llamados a participar. Así pues, la dirección, que todos tenemos que aprender a seguir, en una nueva etapa misionera, es la que Jesús indicó a sus discípulos:"mar adentro", lejos de la seguridad de nuestras orillas. ${ }^{31}$

\subsection{Asociacionismo católico}

Uno de los aspectos en los que se ha manifestado con más fuerza el despertar del laicado a su vocación y su corresponsabilidad eclesiales ha sido la inmensa profusión del asociacionismo desde el pasado siglo. A ello la Iglesia ha dedicado atención reflexiva y pastoral, que aún es preciso seguir profundizando, sobre la base de una eclesiología global. ${ }^{32}$ Como fundamento de esta realidad agregativa en la Iglesia está el derecho de asociación, el cual" deriva del bautismo, en cuanto sacramento que llama a todos los fieles laicos a participar activamente en la comunión y misión de la Iglesia". ${ }^{33}$ Hay que considerar, además, su conveniencia en favor de una mayor profundidad en la formación cristiana de los fieles, la estabilidad de los procesos y la eficacia evangelizadora en los múltiples campos de la misión. La asociación de fieles se trata de un derecho regulado, tanto en lo que se refiere al reconocimiento de nuevas asociaciones, como en lo que concierne a su ejercicio. ${ }^{34} \mathrm{Sin}$ embargo, eso no significa que se trate de una concesión por parte de la jerarquía. Más aún, forma parte de la responsabilidad de los pastores fomentar este derecho asociativo. Ello se expresa de forma inmediata en el establecimiento y la promoción de realidades eclesiales como Cáritas —en el ámbito socio-caritativo—, Manos Unidas —en el terreno de la cooperación internacional— o la Acción Católica General —como cauce ordinario que vertebre la formación cristiana de niños, jóvenes y adultos en el seno de las parroquias-.

\footnotetext{
30 Cf. LG 8; Mt 11,5; Lc 7,22.

31 Cf. Lc 5,4.

32 Cf. AA 19-22; EN 58; CL 29-30; CIC, can. 298-329.

33 JuAN PABLo II, Exhortación apostólica postsinodal Christifideles laici (CL) sobre la vocación y la misión de los laicos en la Iglesia y en el mundo, AAS 81 (1989) 393-521, n. 29. Cf. CIC, can. 215.

34 Cf. infra, 3.2.
} 


\section{MISIÓN EN COMUNIÓN: EL CAMINO SINODAL DE LA IGLESIA}

La Iglesia es misterio de comunión: comunión en el origen (Ecclesia de Trinitate), en el camino y en la meta de la misión (communio sanctorum). En la Iglesia y por ella, todos estamos "llamados a revivir la misma comunión de Dios y a manifestarla y comunicarla en la historia (misión). [...] Sólo dentro de la Iglesia como misterio de comunión se revela la «identidad» de los fieles laicos, su original dignidad. Y sólo dentro de esta dignidad se pueden definir su vocación y misión en la Iglesia y en el mundo". ${ }^{35}$ Teniendo por fundamento esta importancia de la comunión para la justa consideración de la identidad laical, nos centramos en algunos aspectos especialmente importantes para el apostolado seglar, basados en la mutua implicación entre la comunión y la misión.

\subsection{Unidad de la misión y sinodalidad}

Solo desde la consideración de la comunión como entraña del misterio de la Iglesia tiene sentido plantear la responsabilidad de que, en su vida y su misión, se muestre como comunión "orgánica", "análoga a la de un

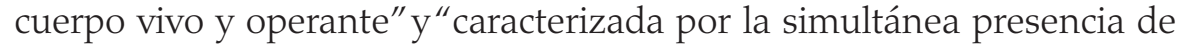
la diversidad y de la complementariedad de las vocaciones y condiciones de vida, de los ministerios, de los carismas y de las responsabilidades" ${ }^{36}$ Para la conjugación de todas las energías, sensibilidades, experiencias y recursos disponibles en la evangelización, es necesario recordar la unidad originaria de la misión, que está en la base de la unicidad y catolicidad de la Iglesia, la cual reclama la concreta unidad, la comunión visible, y a ella conduce.

\subsubsection{Sinodalidad: comunión dinámica y concreta}

El don de la comunión, expresado en la estructura eclesial y su correspondiente unidad doctrinal, litúrgica y disciplinar, se debe manifestar históricamente, a través de lo que se designa desde hace algún tiempo como "sinodalidad" eclesial. ${ }^{37}$ Como manifestación de la dinámica de la

35 CL 8. Cf. LG 4, 7, 9, 13.

36 CL 20.

37 Cf. Francisco, Discurso con ocasión de la Conmemoración del 50 aniversario de la institución del Sínodo de los Obispos (17 de octubre de 2015), AAS 107 (2015) 1138-1144; COMisión TeOlógica Internacional, La sinodalidad en la vida y la misión de la Iglesia, Madrid, BAC, 2018; Santiago MADrigal (ed.), La sinodalidad en la vida y la misión de la Iglesia. Texto y comentario del documento de la Comisión Teológica Internacional, Madrid, 
comunión eclesial, la sinodalidad"expresa el específico modus vivendi et operandi del Pueblo de Dios en la participación responsable y ordenada de todos sus miembros en el discernimiento y puesta en práctica de los caminos de su misión". ${ }^{38}$

La comunión es dinámica, concreta y plural. Por eso encierra una dialéctica peculiar, sin la cual carecería de inserción en la historia. Esta dialéctica puede ser presentada bajo una doble modalidad: a) la comunión es una realidad que va adquiriendo grados distintos de conciencia, la cual se expresa en una concreta forma o figura que exige determinados procesos; b) la comunión en lo concreto de la Iglesia debe conjugar el papel y el protagonismo peculiar de todos (el conjunto de los bautizados), de algunos (que detentan ministerios o competencias diversas) y de uno (que preside y que por ello expresa y garantiza la unidad). ${ }^{39}$

\subsubsection{Pastoral de conjunto}

El concepto de sinodalidad otorga mayor amplitud y, al mismo tiempo, mayor dinamicidad y operatividad al hasta ahora más extendido de pastoral orgánica diocesana o "pastoral de conjunto". Este modo de la pastoral implica una voluntad decidida de ser fieles al mandato misionero, siendo eficaces a través de la coordinación de las instituciones y de las iniciativas. Sin duda, imaginar juntos escenarios de mayor comunión pasa por la responsabilidad de la coordinación de los agentes evangelizadores. La noción de pastoral de conjunto expresa que el sujeto que evangeliza es la Iglesia entera y se concreta en el nivel organizativo, cuando se trata de articular, bajo la dirección de los pastores, la pastoral orgánica de la Iglesia particular como expresión y cauce de la unidad de misión y, por consiguiente, de la unidad del sujeto eclesial de la evangelización.

Todos los proyectos e instituciones: catequéticas, misioneras, caritativas, sociales, familiares y otras con fines pastorales, irán de común acuerdo (ad concordem redigantur actionem), con lo que al mismo tiempo aparecerá mucho más clara la unidad de la diócesis. ${ }^{40}$

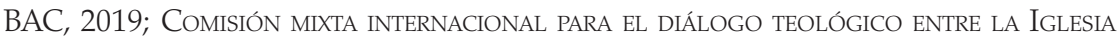
Católica y la Iglesia Ortodoxa, Le conseguenze ecclesiologiche e canoniche della natura sacramentale della Chiesa. Comunione ecclesiale, conciliarità e autorità ("Documento de Rávena", 2007).

38 Comisión TeOlógica Internacional, La sinodalidad, n. 43.

39 Eloy Bueno De la Fuente, "El fundamento teológico de la sinodalidad", Scripta theologica 48 (2016) 645-665; 648.

40 CD 17. Cf. EG 29; 105; CV 202. 
Ahora bien, la noción de pastoral de conjunto no concierne simplemente al modo de organización eclesial, ni debe responder a obsesión alguna por las instituciones, por su propia pervivencia, por el control de los ámbitos de influencia - lo cual denuncia el Papa como un grave defecto de "autorreferencialidad", que, tanto en su aspecto personal como organizativo, hiere la comunión y lastra el impulso misionero- $-{ }^{41}$ Desde luego, no basta entender la comunión eclesial como la coordinación de departamentos estancos, o de iniciativas aisladas y autónomas, que de manera forzada se reúnan esporádicamente para alguna acción común. El foco de la comunión y de la participación sinodal no se encuentra en nosotros y nuestras particulares acciones y expectativas, sino en los destinatarios de la misión: "El objetivo de estos procesos participativos no será principalmente la organización eclesial, sino el sueño misionero de llegar a todos". ${ }^{42}$

\subsubsection{Sinodalidad: unidos en la misión}

Por tanto, para evitar una visión excesivamente centrada en lo organizativo e institucional, es oportuno el desarrollo del concepto de sinodalidad. Un camino sinodal para la Iglesia debe expresar la unidad orgánica de un cuerpo eclesial vivo, donde todos los miembros están referidos los unos a los otros y juntos reciben la vida del mismo Espíritu y el impulso para seguir realizando la misión de extender el Reino. Se expresa así la necesidad de abrir cauces y procesos de discernimiento comunitario, donde se haga posible dar pasos unidos, aportando cada cual el caudal de sensibilidades, experiencias y recursos con los que cuenta, para la misión unitaria de la Iglesia.

Estando así en función de la vitalidad de la misión, la sinodalidad manifiesta, por ello, algo constitutivo de la propia Iglesia, invitándonos a concretar en una acción evangelizadora más fecunda la realidad comunional de la Iglesia," comunión misionera" ${ }^{43}$ Es preciso asumir la responsabilidad de caminar juntos los que hemos sido convocados y enviados por el mismo Señor. "Caminando unidos" (syn-hodói), todos los agentes disponibles han de mostrar la vitalidad de un cuerpo eclesial único, integrado por múltiples miembros. ${ }^{44}$ Que no se trata de un modo opcional de organización y de acción evangelizadora, sino plenamente coherente

\footnotetext{
${ }^{41}$ Cf. EG 8, 94, 95.

42 EG 31.

43 CL 32; EG 23; 31.

44 Cf. 1 Cor 12,12-30; Rm 12,3-8.
} 
con el ser eclesial, se desprende de la siguiente declaración del Papa Francisco, donde describe también el modo de operar sinodalmente:

El camino de la sinodalidad es el camino que Dios espera de la Iglesia del tercer milenio. [...] El camino sinodal comienza escuchando al pueblo, que"participa también de la función profética de Cristo" (LG 12), según un principio muy estimado en la Iglesia del primer milenio: "Quod omnes tangit ab omnibus tractari debet". El camino del Sínodo prosigue escuchando a los Pastores. Por medio de los Padres sinodales, los obispos actúan como auténticos custodios, intérpretes y testimonios de la fe de toda la Iglesia, que deben saber distinguir atentamente de los flujos muchas veces cambiantes de la opinión pública. [...] Además, el camino sinodal culmina en la escucha del Obispo de Roma, llamado a pronunciarse como "Pastor y Doctor de todos los cristianos" (Concilio Vaticano I, Constitución Pastor aeternus, capítulo IV): no a partir de sus convicciones personales, sino como testigo supremo de la fides totius Ecclesiae [...]. La sinodalidad, como dimensión constitutiva de la Iglesia, nos ofrece el marco interpretativo más adecuado para comprender el mismo ministerio jerárquico. ${ }^{45}$

\subsubsection{Evitar equívocos}

Es preciso evitar posibles equívocos acerca de la sinodalidad. En concreto, no puede abrazarse la bandera de la sinodalidad, comprendida reductivamente desde una perspectiva operativa, convertida en plataforma para que quienes tengan más capacidad de influencia puedan ejercerla, $\mathrm{y}$ olvidando su fundamental referencia a la comunión. Precisamente la comunión es "la fuente, la forma, y el objetivo" de la sinodalidad. ${ }^{46}$ Esto significa que el ejercicio sinodal es exigido por la comunión, pero esta a su vez es el alma sin la cual la sinodalidad queda en mero procedimiento sin espíritu y, en fin, todo el camino sinodal está en función de la vitalidad y el crecimiento de la comunidad cristiana, no de proyectos particulares.

Un aspecto esencial en esta referencia a la comunión se encuentra en la complementariedad de fieles y pastores. La sinodalidad desarrolla esta lógica, manifiesta ya en el Concilio, de la conjunción de la diversidad de funciones en favor de la única misión.

Hay en la Iglesia diversidad de ministerios, pero unidad de misión. A los apóstoles y sus sucesores les confirió Cristo la función de enseñar, santificar y gobernar en su propio nombre y autoridad. Pero también los laicos, partícipes de

\footnotetext{
45 Francisco, Discurso con ocasión de la Conmemoración del 50 aniversario.

46 Comisión Teológica Internacional, La sinodalidad, n. 43.
} 
la función sacerdotal, profética y real de Cristo, cumplen en la Iglesia y en el mundo la parte que les corresponde en la misión de todo el Pueblo de Dios. ${ }^{47}$

Esta complementariedad se ha verificado, de hecho, a lo largo de la historia de la Iglesia, en las corrientes reformistas que han sido efectivamente asumidas por la autoridad eclesial y en las reformas emprendidas desde la jerarquía que han logrado alguna eficacia.

Esta unión de una reforma eclesial y el principio sinodal es comprensible: refleja, sin duda, la naturaleza profunda de las cosas. En efecto, se trata de conjugar el movimiento de abajo y la acción de la autoridad, la adhesión de la base y la dirección de los responsables. Una asamblea, sea cual fuere su nombre y su forma - capítulo, sínodo, concilio, congreso—, es un lugar de diálogo en donde puede formarse y afirmarse una voluntad común, donde la autoridad puede actuar teniendo el consentimiento vivo del cuerpo entero. ${ }^{48}$

Así pues, una misión más viva y en comunión apela a la corresponsabilidad eclesial y nos remite también al papel propio de los pastores, que no permite pensar la sinodalidad como una especie de parlamentarismo. ${ }^{49}$ El ejercicio sinodal consiste, precisamente, en poner en juego la complementariedad de funciones en favor de la única misión de la Iglesia. Un estilo sinodal de evangelización se ha de mostrar en eventos y estructuras que den cauce a la participación de todos en los procesos de discernimiento y decisión, de lo cual los pastores son los últimos

47 AA 2. Cf. LG 10; 32; CD 16-17. Cf. José Ramón VILLAR, “Sinodalidad: Pastores y fieles en comunión operativa", Scripta theologica 48 (2016) 667-685; VITALI, art. cit. El arzobispo de Malinas-Bruselas tan influyente en algunos momentos decisivos del Concilio, siendo uno de sus cuatro moderadores y miembro de la Comisión de coordinación se lamenta de que en el mismo texto conciliar no se terminen de sacar las consecuencias de la eclesiología ahí expresada, pues se halla yuxtapuesta a la concepción más institucional del capítulo III sin lograr una perfecta integración. En concreto, advierte que solo se trata "la colegialidad de los obispos como tales, sin conexión vital y permanente con su presbiterio y con su pueblo", y echa en falta un tratamiento de la"colegialidad de la Iglesia", lo cual llamamos hoy sinodalidad. SuENENS, art. cit., p. 186.

48 Congar, Verdadera y falsa reforma en la Iglesia, Salamanca, Sígueme, 2014, 233. Cf. 231-241. Cf. ID., Jalones, 303-306.

49 Las posibilidades y límites de los laicos en el gobierno de la Iglesia, en el marco de su función real, quedan teológicamente fundados y testimoniados históricamente en Congar, Jalones, 286-320. Su papel se concreta en la "información y consejo" y el "consentimiento y difusión", quedando la decisión en manos de los pastores. Acerca de la función diferenciada de fieles y ministerio ordenado, cf. VILLAR, art. cit. Sobre la circularidad y complementariedad entre sensus fidei y las enseñanzas y decisiones de los pastores en el ejercicio de la sinodalidad eclesial, cf. CONGAR, 337-355; 393-395; VITALI, art. cit. Cf. Comisión Teológica Internacional, El sensus fidei en la vida de la Iglesia, Madrid, BAC, 2014, nn. 74-80. 
responsables: consultas al Pueblo de Dios, consejos pastorales diocesanos y parroquiales, delegaciones de pastoral, sínodo diocesano... Esto implica, en lo concreto, la responsabilidad de la escucha y del diálogo en libertad, para la contribución de todos, según su peculiaridad, a la misión. De la responsabilidad de contribuir a esta misión nadie debe ser o considerarse excluido; en la tarea de evangelizar, todas las manos son necesarias, todas las sensibilidades y capacidades han de ser puestas en juego. Pero la responsabilidad de conjugarlas pertenece a los pastores, que deben velar por que no se apague el fuego del Espíritu, ni se pierda tampoco el horizonte original de la Iglesia particular y de la unidad y catolicidad de la misión. Corresponde a los pastores, como garantes de la comunión, presidir los procesos de discernimiento, inicial y continuo, de las diversas iniciativas evangelizadoras implicadas en el camino sinodal de la Iglesia. ${ }^{50}$

\subsection{Los "carismas": dones para la vida y la misión de la Iglesia}

Por su parte, las realidades asociativas fundacionales pueden realizar una contribución muy valiosa a la misión. Es necesario partir de un reconocimiento concreto de la naturaleza, los fines y el alcance diversos de cada una de estas realidades, para de este modo hacer un discernimiento adecuado del mejor engarce posible de cada iniciativa en la misión conjunta de toda la Iglesia. Para que esto sea así, es imprescindible que fieles y pastores desarrollen actitudes respectivas de humildad y acogida:

Cuando se integran con humildad en la vida de las Iglesias locales y son acogidos cordialmente por obispos y sacerdotes en las estructuras diocesanas y parroquiales, los movimientos representan un verdadero don de Dios para la nueva evangelización y para la actividad misionera propiamente dicha. ${ }^{51}$

En la medida en que estas iniciativas son reconocidas por la Iglesia como instrumentos providenciales, son también interpretadas como"carismas". En este sentido las describe así Congar:

Son dones de gracia u ordenados a la realización del propósito divino de salvación, que no proceden de una acción jerárquica regularizada como la del bautismo o la eucaristía, pero que por concurrir al mismo fin de la Iglesia y de ministerio están sometidos a la ley de la unidad y, por eso, dependen en su ejercicio de cierta reglamentación por parte de la autoridad instituida. ${ }^{52}$

50 Cf. LG 12; AA 3.

51 RM 72.

52 Congar, Jalones, 360. Cf. ibid., 356-372; 407-425. 
Esta consideración se enraíza en las enseñanzas paulinas y se desarrolla en el ámbito de la teología de la gracia bajo la categoría de"gracias gratuitamente dadas" (gratiae gratis datae). ${ }^{53}$ La aplicación del concepto de "carisma" a una realidad colectiva en la Iglesia la encontramos implícita en el uso que hace del término"dones" el Decreto conciliar sobre la vida religiosa.

En la Iglesia hay muchísimos institutos, clericales o laicales, dedicados a diversas obras de apostolado. Tienen carismas (donationes) diferentes, según la gracia que se les ha dado: el del servicio, para servir; el de enseñanza, para enseñar; el que exhorta, para exhortar; el de dar, para hacerlo con sencillez; el de la misericordia, con alegría. ${ }^{54}$

En este mismo sentido, enseña el Concilio que el Espíritu Santo"construye y dirige [la Iglesia] con diversos dones jerárquicos y carismáticos" ${ }^{55}$ No es una total novedad, pues, la abierta aplicación del término"carisma" al asociacionismo seglar, como "carismas participados", que encontramos en Christifideles laici:

Los carismas se conceden a la persona concreta; pero pueden ser participados también por otros y, de este modo, se continúan en el tiempo como viva y preciosa herencia, que genera una particular afinidad espiritual entre las personas. ${ }^{56}$

Las iniciativas carismáticas no han faltado ni faltarán nunca en la Iglesia, hasta el punto de que fueron calificadas por Juan Pablo II como "coesenciales", junto con los medios estructurales con los que el Espíritu

53 Cf. 1 Cor 12,1-14,40; Rm 12,6-8; Ef 4,7-11. Cf. STh I, q.43, 3 a.4; I-II q.66, 2 a.1; II-II, q.4, 5 a.4; 45, 5; 63, 2; 171 prol.; 172, 2 a.2; III, q.27, 6. Tomo estas citas de Card. Albert VAnHoye, I carismi nel Nuovo Testamento, Roma, Gregorian \& Biblical Press - SDS Edizioni, 2010.

54 PC 8. Cf. Cf. PC 1 y, referido al seguimiento de los consejos evangélicos, PC 12 y 14.

55 LG 4. Es interesante observar que los carismas forman parte del conjunto más amplio de dones con los que el Espíritu fortalece a la Iglesia, incluido el ministerio ordenado. En el contexto de esta relación entre carisma e institución en la Iglesia, subraya el fundamento sacramental del ministerio eclesiástico Card. Joseph RATZINGER, "Los movimientos eclesiales y su colocación teológica", Communio (1999/1) 87-108 (pp. 89-91). En el mismo sentido, Congar se refiere con diversas expresiones al "carisma de apostolicidad", "don que acompaña al orden". Congar, Jalones, 329; 357; 362. Conviene también observar que, si bien la multiplicidad de dones no puede quedar subsumida en el ministerio, tampoco quedan excluidos los ministros de recibir dones carismáticos; más bien, en los ministros ordenados han de fundirse los aspectos ex officio y ex spiritu. Cf. ibid., 416-418.

56 CL 24. Juan Pablo II interpreta aquí en este sentido colectivo también la referencia a "dones" $y$ "carismas" que encontramos en AA 3. 
del Señor dota también a su Iglesia para su vida y su misión —la Palabra, los sacramentos, el ministerio ordenado- ${ }^{57}$ Por eso, para una mejor conjugación en la concreta vida y acción evangelizadora de las Iglesias particulares, resulta imprescindible ahondar en la teología de los carismas, tanto en su vertiente personal como en su interpretación derivada, aplicada a realidades fundacionales históricas y a agregaciones de fieles recientes. ${ }^{58}$ Estas pueden reconocerse como dones del Espíritu, siempre que encuentren su utilidad y el criterio para su reconocimiento y ejercicio en la renovación y el crecimiento del cuerpo de la Iglesia. Estas condiciones de renovatio y amplior aedificatio traducen el criterio paulino del“bien común" de la Iglesia..$^{59}$ En ningún caso las iniciativas carismáticas pueden pretender ser manifestación de una economía del Espíritu separada de la delVerbo, hasta el punto de que podamos considerar dos Iglesias paralelas: la institucional, por un lado, y la carismática, por otro. ${ }^{60}$

En este sentido, la experiencia de los últimos decenios nos invita a evaluar cierta inflación en la apelación a los "carismas", que no siempre es garantía de una mayor vitalidad de la comunidad cristiana, sino que a veces tiende a disipar sus fuerzas. Es preciso evitar una interpretación errónea de la realidad espiritual y eclesial de los carismas, que lleve a una falsa mistificación de la comunión y de la misión, por la cual se multiplica cierta aplicación impropia o abusivamente exclusiva de términos -"consagración", "vocación", "envío", "comunidad", "carisma"—, que quedan así hipertrofiados. ${ }^{61}$

\subsubsection{Pueblo de consagrados}

Todos los cristianos hemos sido consagrados por el bautismo y la confirmación. Visto esto, una dedicación personal preferente a esta u otra realidad, ¿puede designarse responsablemente como una "consagración" nueva, sentida incluso como superior a la bautismal? Más bien, habría que entender que la consagración bautismal es la fuente de todo

57 Cf. Juan Pablo II, Discurso a los movimientos eclesiales con motivo del II Coloquio internacional (2 de marzo de 1987), n. 3.

58 Cf. Ratzinger, art. cit.; Congregación para la Doctrina de la Fe, Carta Iuvenescit Ecclesia (IE) sobre la relación entre los dones jerárquicos y carismáticos para la vida y misión de la Iglesia (2016).

${ }_{59}$ Cf. LG 12; AA 3; 1 Cor 12,4.

60 Cf. IE 11.

61 A las cautelas que a continuación se presentan, sugeridas por la experiencia pastoral, pueden añadirse las que señala CONGAR, Jalones, 418-425. Lo hace también a través de algunas precisiones terminológicas: "voluntad de Dios, santa y santificante", "vocación","compromiso y responsabilidad", "servicio". Cf. ibid., 520-544. 
compromiso en favor del Reino. Esta convicción está justamente en la base de todo el despertar del laicado en el pasado siglo. En este momento en que, paradójicamente, proliferan los intentos de distinción por vía de pretendidas nuevas consagraciones laicales, conviene recordar al respecto la enseñanza conciliar, que describe así la raíz - insuperablemente sublime — de todo el apostolado seglar:

El deber y el derecho de los laicos al apostolado derivan de su misma unión con Cristo cabeza. Incorporados por el bautismo al cuerpo místico de Cristo y fortalecidos con la fuerza del Espíritu Santo por medio de la confirmación, son destinados al apostolado por el mismo Señor. ${ }^{62}$

\subsubsection{Llamados y enviados}

Es también necesario revisar las nociones de "vocación" y el sujeto de la llamada y del envío para una tarea determinada. La vocación a la comunión con Dios es el fundamento mismo de la dignidad de cada persona, con quien Dios desea entablar un diálogo de amor ininterrumpido. ${ }^{63}$ Por la fe, además, todos nos reconocemos llamados por Dios en nuestros concretos itinerarios vitales. En lo que concierne a la función profética, en la cual el Concilio enmarca la cuestión de los "carismas", el derecho canónico declara con claridad algunas implicaciones prácticas: "los fieles laicos [...] pueden ser llamados a cooperar con el obispo y con los presbíteros en el ejercicio del ministerio de la palabra". ${ }^{64}$ Esta afirmación sobre la capacidad de ser llamados contrasta con la función propia de los presbíteros, declarada un poco antes:"es propio de los presbíteros, como cooperadores de los obispos, anunciar el evangelio de Dios". ${ }^{65}$ Nótese que no se dice que esta función sea propia en absoluto, sino en calidad de cooperadores y, por tanto, en el marco de la Iglesia particular y del papel que en ella tiene el obispo de"moderador de todo el ministerio de la palabra". ${ }^{66}$ Así pues, quienes tienen capacidad de "llamar" $\mathrm{y}^{\prime \prime}$ enviar" en nombre del Señor en la Iglesia son los pastores, sin perjuicio de lo que corresponda a la vida interna de cada agregación.

\footnotetext{
62 AA 3.

63 Cf. GS 19.

64 CIC, can. 759. La referencia al derecho canónico, como expresión autorizada de una necesaria función reguladora en la vida de la Iglesia y en su misión, se hace inevitable en un estudio sobre el apostolado seglar que integra una orientación práctica, no solo interpretativa.

65 CIC, can. 757

66 CIC, can. 756, §2.
} 
Confusiones en este aspecto se convierten en graves distorsiones y dificultades en la configuración de las comunidades y en la eficacia de la acción evangelizadora, cuando algunos laicos se arrogan funciones, ya sea por propia iniciativa o empujados por su organización. Nadie debe desempeñar un ministerio en una comunidad partiendo de su propia iniciativa, ni basta que lo proponga alguien, tampoco un ministro ordenado, obviando al responsable de la cura pastoral de una comunidad concreta. De este modo, los laicos capacitados y llamados a desempeñar su necesaria colaboración en la comunidad, lo deben hacer bajo la coordinación y la supervisión de los ministros ordenados, a quienes corresponde como función propia ese servicio en favor de toda la acción pastoral, lo cual tampoco realizan por iniciativa personal.

Esto no implica, en modo alguno, que el apostolado lo ejerzan los laicos como por delegación de los pastores. En lo que concierne a su“vocación propia", ${ }^{67}$ desde luego no es así; son enviados inmediatamente "por el mismo Señor". ${ }^{68} Y$ así hay que entenderlo en modo general (no inmediato) acerca de su capacidad y disposición al apostolado también en el ámbito intraeclesial de las comunidades, a través del ministerio de la catequesis, la caridad, la liturgia y otros. ${ }^{69}$ Pero el peligro de una "funcionalización del laicado", cuando se tiende a recluir su aportación solo al ámbito intraeclesial, es muy evidente. ${ }^{70}$ Se trata entonces de una deficiente promoción del apostolado laical, que ha contribuido a extender la enfermedad del clericalismo y que se sitúa en la inercia de los modos de acción eclesial de la cristiandad, sin una verdadera perspectiva misionera.

\subsubsection{Carisma e institución}

Por su parte, apelar al "carisma" ¿puede ser aval o patente de corso para desarrollar un apostolado al margen del resto de la vida de la Iglesia, o sin ser expresión de la comunidad cristiana como sujeto eclesial, ni revertir en su vitalidad y cohesión? Un carisma no está llamado a expresarse directamente en un ministerio en la Iglesia, desarraigado de la realidad orgánica de la comunidad cristiana, pues la Iglesia no ha recibido una "estructura carismática". ${ }^{71}$ En consonancia con el derecho de asociación

67 LG 31.

68 AA 3.

69 Cf. EN 73.

70 Francisco, Carta al Cardenal Marc Ouellet.

71 Cf. VAnHoYe, op. cit., 23-27. El autor hace en estas páginas una lectura crítica de esa propuesta de Hans KüNG, Ser cristiano, Madrid, Cristiandad, ${ }^{3} 1977,615-627$. Para el teólogo suizo, esta noción se remonta a la constitución de las Iglesias paulinas, según 
en la Iglesia, que se anima a ejercer "con sus propias iniciativas, cada uno según su estado y condición", ${ }^{72}$ alguien podría aducir el principio de subsidiariedad, de modo que deba respetarse sin más cualquier iniciativa apostólica y la autoridad eclesiástica solo interviniera de manera subsidiaria. ${ }^{73}$ Puede haber y hay muchas iniciativas apostólicas legítimas de agregaciones eclesiales, en las cuales puede verse reflejado en cierto modo este principio, cuando siguen "una buena via facti".$^{74}$

En cambio, ocurre también que se tiende a mirar con benevolencia cierto desarrollo anárquico del asociacionismo, con claras fallas en lo que concierne al derecho: en estos la ausencia de estatutos, en aquellos la falta de comunicación con el Ordinario, en estos otros un desarrollo paralelo a la pastoral ordinaria de la diócesis... ${ }^{75}$ Es interesante, al respecto, recordar los fines que reconoce el derecho canónico a la iniciativa de asociación: "para fines de caridad o piedad o para fomentar la vocación cristiana en el mundo". ${ }^{76}$ Entre estos fines — diaconía, espiritualidad, incidencia social de los valores evangélicos- no se encuentra fundar comunidades de gente selecta que viva su fe aparte del resto de bautizados. Precisamente, someter al juicio de la jerarquía la inspiración fundacional y su realización práctica es antídoto frente a la tentación de sectarismo y garantía de un esfuerzo de reforma dentro de la Iglesia, sin pretensiones exclusivistas de un cristianismo puro y auténtico. Tampoco forma parte de esos fines posibles organizar la vida de las comunidades cristianas para troquelarlas según una inspiración fundacional concreta, proponiendo

su opinión hoy desfasada, como "comunidades de libres servicios carismáticos" (p. 623) y debería permitir, en consecuencia, una pluralidad de modos de configuración del servicio de dirección en la Iglesia actual.

72 Cf. CIC, can. 216.

73 Esto puede verse en la imagen de la "Iglesia como familia", con su concreción en la parroquia como"cuerpo intermediario", lo cual opone Congar a la imagen de "Iglesia como ciudad". Cf. Congar, Jalones, 316. Puede verse también en la relación entre las nociones de "comunión entre" y"comunión con". Cf. ibid., 402-407.

74 Se trata de una "vía de los hechos" que puede ser acogida cordialmente, cuando "la periferia o el abajo propone al centro o a la autoridad sus querellas, sus ensayos, sus esperanzas, sometiéndolo todo al juicio de quien tiene el deber y el carisma de juzgar"; de este modo hay "muchas iniciativas laicas, gracias a las cuales los fieles hacen de verdad la Iglesia y van formando, a través del espacio y del tiempo, su cuerpo, su figura histórica". CongAr, Jalones, 306.

75 Los estatutos son de obligada provisión para las distintas agregaciones de fieles (cf. CIC, can. 304 §1). El desarrollo de sus actividades apostólicas debe ser supervisado por la autoridad eclesiástica competente (cf. CIC, can. 305). En lo que respecta a las asociaciones ligadas a institutos de vida consagrada, ha de velarse por que contribuyan coordinadamente al apostolado de toda la diócesis (cf. CIC, can. 311).

76 CIC, can. 215. 
abusivamente como medios ordinarios y generales los que solo pueden entenderse como libres y particulares. Ante estas situaciones conviene recordar: "la institución salva la inspiración; el derecho protege la vida; en el cuerpo de Cristo, que es la Iglesia, el espíritu encuentra un cuerpo, y al animar este cuerpo es conservado con él" ${ }^{77}$ Detrás de esta consideración se encuentra la interrelación entre las categorías "estructura" y "vida", a la cual Congar otorga una fuerte capacidad explicativa del misterio de la Iglesia. ${ }^{78}$

\subsubsection{Al servicio de la comunidad}

Una buena comprensión del principio de subsidiariedad, aplicado a la Iglesia, no debe pasar por alto que el sujeto de la misión no lo constituye un grupo particular y aislado, como tampoco pueden serlo los fieles al margen de los pastores (o viceversa), sino la comunidad cristiana como célula irreductible de eclesialidad. ${ }^{79}$ Esto debe tenerse en cuenta, sobre todo, acerca de las plataformas de evangelización básicas y comunes, en particular de la parroquia, en las cuales el ejercicio de la subsidiariedad no puede implicar una delegación indefinida en favor de iniciativas fundacionales, a modo de privatización de la acción evangelizadora ${ }^{80}$ En tal caso, se estaría dando un indebido y fatal paso del plano de la vida al de la estructura. ${ }^{81}$

Es necesario, en este punto, detenerse en el concepto eclesiológico de "comunidad", por ser la concreción más evidente de la comunión eclesial. Es a la Iglesia particular a la que conviene, como analogado principal, la designación de"comunidad", pues"en ella está verdaderamente presente y actúa la Iglesia de Cristo una, santa, católica y apostólica", ${ }^{82}$ la

77 COngar, Verdadera y falsa reforma, 244.

78 Cf. ID. Jalones, 311-313 y passim.

79 Esto tiene que ver con la Iglesia como institución: “En el orden natural, la autoridad es, en su forma positiva, un órgano que se impone el cuerpo político, en la necesidad, pero también en la capacidad, que tiene de organizarse a sí mismo; dentro del orden de salvación, la autoridad es dada juntamente con el cuerpo, de tal manera que le es anterior, al menos lógicamente [...]." CongAR, Jalones, 305.

80 Acerca del resultado" catastrófico" en la historia de la Iglesia del" sistema de propiedad de un laico particular o de una sociedad de laicos sobre la iglesia parroquial", donde "un grupo de laicos se había arrogado el derecho de elegir al párroco, al que financiaban, de regular el alquiler de los bancos, el uso de la iglesia y los locales", cf. Congar, Jalones, 308. Sobra decir que una reedición de este experimento pastoral, bajo nuevas formas, dará probablemente un resultado similar. En ello ve el teólogo dominico la razón por la cual "el derecho canónico no haya reconocido personalidad jurídica a la comunidad de fieles como tal". Ibid.

81 Cf. CONGAR, Jalones, 311.

82 CD 11. 
cual es "comunidad de fe, esperanza y caridad" ${ }^{83}$ De forma derivada, se aplica a las parroquias, que respecto a la diócesis son "como una célula", ${ }^{84}$ constituidas por el obispo "necesariamente" y que "en cierto modo representan a la Iglesia visible establecida por todo el mundo". ${ }^{85} \mathrm{La}$ parroquia es comunidad eucarística y orgánica, "lugar de la comunión"86 y "modelo preclaro de apostolado comunitario al congregar en unidad todas las diversidades humanas que en ella se encuentran, insertándolas en la universalidad de la Iglesia" ${ }^{87}$ En ella la Iglesia aparece con todos sus elementos esenciales, que le permiten dar a luz a sus hijos y acompañarlos en su crecimiento hacia Cristo hasta hacer de ellos los discípulos que puedan dar testimonio del evangelio en medio de una realidad social concreta. Cualquier otra realidad eclesial participa de la esencial dimensión comunitaria, lo cual remite a aspectos humanos y sociales que no se pueden desdeñar, por ser la Iglesia también coetus adspectabilis; ${ }^{88}$ por eso, puede ser designada, de manera parcial y analógica, como "comunidad". ${ }^{89}$ Pero, no pudiendo por sí misma generar la comunidad cristiana, no debe borrar de su horizonte y del de sus miembros la participación en su comunidad parroquial, a la cual pertenecen por razón del bautismo, donde se expresa y alimenta la comunión eclesial, especialmente en la eucaristía dominical. ${ }^{90}$ La pretensión, en cambio, de

83 LG 8.

84 AA 10.

85 SC 42. Acerca de esta condición estable de la parroquia en la Iglesia, el Papa Francisco ha ofrecido algunas declaraciones muy firmes. "La parroquia no es una estructura caduca" (EG 28). Cf. Francisco, Encuentro con los obispos de Polonia (27 de julio de 2016), AAS 108 (2016) 885-896. “ ¡La parroquia es siempre válida! La parroquia debe permanecer: es una estructura que no debemos tirar por la ventana. [...] [Es] una cosa análoga a la estructura episcopal, es diferente, pero análoga. La parroquia no se toca." Ibid., pp. 892-893.

86 CL 26-27. Cf. Gabriel Richi Alberti, "La parroquia, lugar de comunión eclesial", en Gerardo del Pozo - Juan Carlos Carvajal (ed.), Parroquia misionera, Madrid, Universidad San Dámaso, 2018, 77-105.

87 AA 10.

88 Cf. LG 8.

89 Cf. Congar, Jalones, 407-418. Este aspecto comunitario es característico de muchas realidades fundacionales, pero no exclusivo, pues refleja una dimensión esencial de la Iglesia. Respecto a una patrimonialización indebida del concepto de comunidad, no es ocioso recordar la preferencia por este término, cargado de connotaciones antiinstitucionales, ya en el inicio de la crisis protestante. Cf. KüNG, Ser cristiano, 609. Respecto a las "pequeñas comunidades" o "comunidades de base", PabloVI establece las imprescindibles cautelas en EN 58. Asimismo, respecto a todas las agregaciones de fieles se detallan algunos"criterios de eclesialidad" en CL 30 y IE 18.

90 Cf. SC 42; LG 28; JuAn Pablo II, Carta apostólica Dies Domini sobre la santificación del Domingo, AAS 90 (1998) 713-766, n. 34; IGMR 113. 
hacer de estas realidades"una alternativa a la parroquia"91 condena a sus miembros a una experiencia de desarraigo," como nómadas sin raíces", 92 y hurta a la comunidad cristiana una vitalidad que está destinada a enriquecer la vida y la misión de toda la Iglesia.

\subsubsection{Armonía pluriforme}

Para referirse a la belleza pluriforme de la Iglesia, el Papa Francisco usa la imagen del poliedro. ${ }^{93}$ Con otra imagen, Congar hablaba de la "trama" de la Iglesia, como la de un tapiz formado por hilos de diversos colores, dispuestos armónicamente y con un sentido. ${ }^{94}$ Esta pluriformidad, sin embargo, si es eclesial se sostiene en una urdimbre, no está desarticulada ni está movida por una fuerza que la disgregue en mil realidades aisladas y anárquicas. Es ciertamente fruto del Espíritu Santo, que es principio de la bella diversidad eclesial; pero que, al mismo tiempo, es principio de vitalidad, cohesión y crecimiento de la Iglesia, cuerpo de Cristo. El Espíritu, que sopla cuando y donde quiere, siempre lo hace en la misma dirección: la construcción y la vitalidad del cuerpo eclesial, en su unidad multiforme. ${ }^{95}$ En ello se puede reconocer la autenticidad del origen de cada iniciativa y la fidelidad a su impulso primero, que nunca deberían desembocar en la dispersión de las comunidades y de su vitalidad. ${ }^{96}$

Ayudaría mucho a afrontar estos perennes conflictos que se comprendiera mejor la realidad y el sentido eclesial de los carismas ordinarios, a los que únicamente puede remitirse de forma plausible la consideración colectiva de la categoría "carisma", como carismas para el servicio. ${ }^{97}$ De este modo, se ayudaría a considerar esta realidad eclesial con mayor

91 Francisco, Encuentro con los obispos de Polonia, 893: “Los movimientos no deben ser una alternativa a la parroquia: deben ayudar en la parroquia."

92 EG 29. Cf. EG 105.

93 Cf. CV 207.

94 Cf. Congar, Jalones, 396-407.

95 Cf. Jn 3,8. Cf. Benedicto XVI, Homilía en el encuentro con movimientos y nuevas comunidades eclesiales (6 de junio de 2006), AAS 98 (2006) 503-510.

96 Cf. AA 19.

97 El Concilio no olvida la realidad de los carismas "extraordinarios", junto a los ordinarios. Congar menciona los carismas del período fundacional de la Iglesia, las revelaciones privadas y ciertas "anticipaciones de los bienes escatológicos". Cf. Congar, Jalones, 283; 359-361. Una consulta a cualquier manual de teología mística anterior al Concilio nos da idea de la condición verdaderamente excepcional de los carismas, cuando son entendidos como causa de fenómenos místicos extraordinarios, lo cual no admite fácilmente su interpretación derivada como carismas compartidos. Cf. Adolphe Tanquerey, Compendio de Teología Ascética y Mística, Madrid, Palabra, 1990; Antonio Royo Marín, Teología de la perfección cristiana, Madrid, BAC, 1962. 
modestia como el hecho de que, gracias a Dios, hay personas y grupos dispuestos y capaces de realizar lo que, simplemente, alguien debe hacer, en favor del crecimiento, la renovación y la vitalidad de la comunidad cristiana. Este reconocimiento, desde la fe, de la acción providencial del Espíritu es el que permite la misma consideración de una determinada realidad personal o asociativa como "carisma". De hecho, los carismas ordinarios no son sino la asunción y elevación en la vida cristiana de los dones naturales y de la indeterminada pluralidad de circunstancias en las cuales estos dones se desarrollan en favor del Reino. ${ }^{98}$ Esta condición ordinaria de servicio se hace más patente en aquellos casos, los más frecuentes, en los que una iniciativa apostólica ha realizado labores de suplencia, cuando una situación de especial debilidad eclesial no permitiría atender, sin esa providencial ayuda, servicios esenciales que son responsabilidad de toda comunidad cristiana madura. La oración, la caridad, la formación cristiana de niños, jóvenes o adultos..., difícilmente pueden caracterizarse como rasgos distintivos respecto a la tarea ordinaria de cada comunidad. Apelar al "carisma" como elemento distintivo, en estos casos, no puede sino calificarse como ínfulas que desdicen de cualquier verdadero don del Espíritu de santificación y de unidad. Para una visión equilibrada, no está de más atender a las enseñanzas y cautelas que san Pablo nos legó en sus cartas, y que siguen vigentes para nosotros hoy, en medio de las ambigüedades y dificultades que continuarán hasta el final de la historia, como fruto de nuestra inclinación al pecado y signo de nuestra condición peregrina. ${ }^{99}$

En fin, no debemos confundir la audacia de la misión con la temeridad. Una confusión en este terreno y una dejación lamentable del discernimiento comunitario, en la práctica, lleva a las Iglesias locales hacia una deriva de protestantización de la pastoral, análoga a lo que en el terreno doctrinal supone el libre examen de la Escritura. ${ }^{100}$ Frente a las tentaciones del proselitismo y la atomización eclesial, hay que tener presente a la entera comunidad cristiana como sujeto, matriz y meta de la misión. ${ }^{101}$

\subsubsection{Discernimiento pastoral}

A este respecto, también la complementariedad entre fieles y pastores debería plasmarse en discernimientos conjuntos y decisiones pastorales. Es

98 Cf. CONGAR, Jalones, 410-413.

99 Cf. A. VanhoYe, op. cit.; Álvaro Pereira Delgado, Primera carta a los Corintios, Madrid, BAC, 2017, 267-414.

100 Ya realiza esta advertencia CONGAR, Jalones, 419.

101 Pueden leerse otras consideraciones en este mismo sentido en Francisco CASTRO PÉReZ, "La feria de los carismas", Proyección 66 (2019) 405-422. 
responsabilidad de los pastores reconducir algunas prácticas pastorales que se han mostrado, con el paso del tiempo, como una experiencia fallida de revitalización de toda la Iglesia; pues"el remedio no puede venir de las ramas al tronco, sino que tiene que llegar desde las raíces y desde el tronco hasta la rama más lejana" ${ }^{102}$ Un mejor encaje posible y necesario de las realidades fundacionales debe pasar por el discernimiento común y la disponibilidad para proyectos compartidos y evaluables en el marco de la evangelización dirigida por los pastores en cada diócesis. Puede cundir el rechazo, motivado por una cultura dominante alérgica a toda referencia a la autoridad, a que se recuerde la función de gobierno de los pastores. Ciertamente, desde el reconocimiento de una participación bautismal en las funciones sacerdotal, profética y real de Cristo, el munus regendi hay que entenderlo como servicio al sacerdocio real del Pueblo de Dios. ${ }^{103}$ Ahora bien, esto incluye ciertas capacidades propias de gobierno en favor de la comunión y de la misión, de modo que las múltiples iniciativas puedan"permanecer en la comunión del todo" ${ }^{104}$ Frente a la tentación del atomismo eclesial y de la dispersión de las escasas fuerzas disponibles, conviene recordar algunas palabras del Concilio al respecto, de gran equilibrio entre los polos de la vida y la estructura, entre el libre desarrollo del don y el papel regulador de los pastores.

De la recepción de estos carismas, incluso de los más sencillos, surge en cada uno de los creyentes el deber y el derecho de ejercerlos, en la Iglesia y en el mundo, con la libertad del Espíritu Santo, que sopla donde quiere (Jn 3,8), y al mismo tiempo en comunión con sus hermanos en Cristo, y en especial con los pastores, a quienes corresponde juzgar sobre la auténtica naturaleza y el ordenado ejercicio de esos carismas, no ciertamente para apagar el Espíritu, sino para probarlo todo y retener lo que es bueno (cf. 1 Tes 5,12.19.21)..$^{105}$

Guardando la relación debida con la autoridad eclesiástica, los laicos tienen derecho a fundar asociaciones, a dirigirlas y a afiliarse a las ya fundadas. Ha de evitarse, sin embargo, la dispersión de fuerzas que tiene lugar cuando se promueven, sin razón suficiente, nuevas asociaciones y actividades o cuando se mantienen inútilmente asociaciones y métodos ya anticuados; no siempre será oportuno que las formas que se han establecido en una nación se trasladen indiscriminadamente a otras..$^{106}$

102 Card. Fernando Sebastián Aguilar, Claridad y firmeza. Transmitir la fe hoy en España, Madrid, Publicaciones claretianas, 2019, 185. Cf. ibid., 180-185.

103 Cf. CD 16.

104 Cf. Congar, Verdadera y falsa reforma, 223-254.

105 AA 3.

106 AA 19. 
Las posibilidades para la evangelización ahí señaladas siguen vigentes, como también las cautelas. También hoy se debe evitar la multiplicación de iniciativas que pretendan, sin justificación suficiente $-\mathrm{y}$ a veces fuera de todo reconocimiento estatutario, bajo la excusa de ser solo"métodos o instrumentos" - agrupar nuevas confraternidades, empleando en ello fuerzas que deberían servir más bien para vigorizar nuestras endebles comunidades. En el mismo sentido, es preciso ayudarnos en un camino que incluye la posibilidad, y a veces la urgencia, de hacer converger los esfuerzos. En su caso, hay que decirlo, esa convergencia puede implicar, tras un discernimiento franco y compartido, la disolución de determinadas organizaciones. Hay servicios que, providencialmente, han sido cubiertos por iniciativas y que, una vez asumidos en su sustancia por toda la Iglesia, pierden su razón de ser organizativa. Un "carisma", entendido a veces de forma reductiva y errónea como una sanción jurídica en forma de estatutos, no está llamado necesariamente a perdurar. Sobre todo, si ha servido para suscitar un servicio necesario en un momento histórico concreto, realizando así una labor de suplencia, y que ya haya sido suficientemente acogido y promovido por la entera Iglesia. Una vez que el Espíritu Santo, que a todos nos guía, nos ha indicado un camino, nos ha recordado a todos algún aspecto esencial antes desdeñado, entonces la particularidad del carisma ya ha cumplido su función, pasando lo aprendido y conseguido a ser patrimonio de todos.

\subsection{Comunión misionera: un "nosotros" que incluye a todos}

La comunión se trata más de una responsabilidad que afrontar, como respuesta a un don, que una realidad que pueda contemplarse lograda en ninguna etapa ni realización parcial de la experiencia eclesial. Sobre todo, no podemos hablar de comunión y pensarla como organización de los fuertes y capaces, o como reunión de los afines. La verdadera comunión se manifiesta en la consideración de las partes más débiles del cuerpo eclesial y se despliega como un dinamismo de integración de la diversidad.

En un clima de verdadera comunión, dentro de los cauces de la apertura mutua a la verdad y al bien, cabe también un cierto espíritu crítico y profético. Expresado, además, de mil modos y por mil vías en nuestra era de las comunicaciones, las críticas de propios y ajenos pueden ser también asumidas como ayuda a que nos dispongamos verdaderamente a la reforma siempre necesaria. En la medida en que se ejerza con caridad y esperanza como algo que nos concierne, en un clima y disposición de sentire cum Ecclesia, y no como crítica farisaica a una Iglesia de la que en 
el fondo nos desligamos con desafección, fundados en razones convertidas en absolutos. ${ }^{107}$ La reforma en la Iglesia podrá llevarse adelante con la ayuda del Señor y la implicación de todos, a través de una conversión que necesariamente es antes personal que pastoral.

El dinamismo eclesial de unidad, que no debe excluir a nadie, ${ }^{108}$ ha de manifestarse especialmente como una fraternidad inclusiva de los pobres. La comunidad cristiana, como criterio de la autenticidad de su comunión, tiene el reto de la integración social y comunitaria de aquellos con quienes el Señor quiso identificarse especialmente. ${ }^{109}$ Este reto adquiere hoy tintes de particular urgencia ante la injusticia social que deja cada vez más hermanos en los márgenes ${ }^{110} \mathrm{y}$, asimismo, ante el drama de las migraciones forzosas, donde la caridad nos exige" acoger, promover, proteger e integrar". ${ }^{111}$

El modelo del camino sinodal de la Iglesia y el sustento cotidiano de la comunión lo encontramos en la eucaristía. ${ }^{112}$ En torno a ella se reúne y de ella se alimenta el entero Pueblo de Dios. Con la ayuda del Señor, que nos convoca, nos fortalece y nos envía, es necesario que imaginemos y pongamos en marcha escenarios de una mayor comunión en la misión, que impliquen a todos y sean más expresivos de la unidad de la Iglesia y de su misión. De ello puede esperarse un testimonio eclesial más creíble y un servicio a la sociedad más evangélico.

\section{FORMACIÓN PARA LA MISIÓN}

En íntima conexión con la evangelización y con la comunión, hay que considerar la constitución de los discípulos y apóstoles en el seno de la comunidad cristiana. La dimensión formativa incide, pues, de forma directa en la obediencia al mandato de Cristo de "hacer discípulos". ${ }^{113}$

107 Cf. Congar, Verdadera y falsa reforma, 171-194; 211-222. El mismo autor se refiere a la corrección fraterna, en el marco de la independencia de conciencia y como signo de la realeza y libertad espirituales, y al papel de la opinión pública en la Iglesia en Jalones, 284-285; 314-315.

108 Cf. EG 14.

109 Cf. Mt 25,40; EG 177-216.

110 Conferencia Episcopal Española, Iglesia servidora de los pobres. Instrucción pastoral, Madrid, Edice, 2015.

111 Francisco, Mensaje para la Jornada Mundial del Migrante y el Refugiado (14 de enero de 2018), AAS 109 (2017) 918-923.

112 Cf. Comisión Teológica Internacional, La sinodalidad, 47-48; SC 10; Benedicto XVI, Exhortación apostólica postsinodal Sacramentum caritatis sobre la Eucaristía fuente y culmen de la vida y de la misión de la Iglesia, AAS 99 (2007) 105-180, nn. 70-92.

113 Cf. Mt 28,19. 
Con el trasfondo de la reforma eclesial puesta en marcha desde el último Concilio, la responsabilidad que todos tenemos de evangelizar se concreta, para cada diócesis y para sus instituciones dedicadas a la transmisión de la fe, en la necesidad de actualizar y asumir proyectos diocesanos globales de formación del laicado. ${ }^{114}$ Es necesario considerar en qué consiste la formación cristiana y cuáles son sus principales características, que permitan realizar planteamientos acertados a la hora de organizar este aspecto de la evangelización en cada Iglesia particular.

\subsection{El don y la responsabilidad de la formación}

La cuestión de la formación cristiana nos sitúa ante el aspecto más ineludiblemente personal de la transmisión de la fe. Se trata de la constitución del sujeto creyente, de la figura del discípulo, que solo puede ser fruto de la gracia y de una respuesta generosa y fiel de los creyentes y de toda la Iglesia. El don de la formación cristiana genera, en cada uno de los fieles y en la entera comunidad eclesial, la responsabilidad de cuidarla. ${ }^{115}$

Formación significa adquirir forma. Formación cristiana significa adquirir la forma de Cristo, por la cual somos hechos testigos de su vida: su misma forma de pensar, de sentir y de actuar. ${ }^{116} \mathrm{El}$ tema de la configuración con Cristo atraviesa toda la reflexión paulina, sirviendo para describir uno de los aspectos nucleares del misterio de la vida cristiana. Forma parte del designio divino de crearnos y salvarnos, por el cual estamos predestinados a"reproducir la imagen de su Hijo, para que él fuera el primogénito entre muchos hermanos" ${ }^{117}$ Esto se realiza ya incipientemente en el comienzo de la vida cristiana, por el bautismo: "bautizados en Cristo Jesús", "revestidos de Cristo", quedamos vinculados místicamente a su muerte y resurrección para vivir una vida nueva. ${ }^{118}$ Esta "nueva

114 Cf. Congregación para el Clero, Directorio General para la Catequesis (1997), n. 274; Conferencia Episcopal Española, La Iniciación Cristiana. Reflexiones y orientaciones (1998) (ICRO), n. 16.

115 Cf. CL 57-63.

116 Cf. Jn 13,34 ("Os doy un mandamiento nuevo: que os améis unos a otros; como yo os he amado, amaos también unos a otros"; cf. Jn 15,12); Jn 14,12 ("el que cree en mí, también él hará las obras que yo hago"); 1 Cor 2,16 ("Nosotros tenemos la mente de Cristo"); Flp 2,5.21 ("Tened entre vosotros los sentimientos propios de Cristo Jesús. [...] Todos buscan su interés, no el de Jesucristo"). Podrían multiplicarse las citas: la vida entera del discípulo, tal como se plantea en los escritos neotestamentarios, es configuración con Cristo, contemplada bajo diversas perspectivas (seguimiento, imitación, comunión, vida en Cristo...).

117 Rm 8,29.

118 Cf. Rm 6,1-14; 7,4; Gal 3,7. 
condición" conlleva un dinamismo de progresiva asimilación:"Os habéis despojado del hombre viejo con sus obras, y os habéis revestido de la nueva condición que, mediante el conocimiento, se va renovando a imagen de su Creador".${ }^{119}$ Ciertamente, la configuración con Jesucristo es un verdadero milagro de la gracia, que se realiza inicialmente por la fe y el bautismo y que solo el Espíritu Santo puede llevar paulatinamente a plenitud en la persona que acoge el evangelio. Para ello se requiere también la mediación eclesial, pues para eso convocó y envió Jesús a su Iglesia; como Dios se sirvió de María, la humilde sierva del Señor, "dichosa por haber creído", ${ }^{120}$ en cuyo vientre dio el Espíritu Santo forma humana al Verbo eterno, para salvación de todos.

A esta luz comprendió el apóstol Pablo su propia existencia como creyente:"vivo, pero no soy yo el que vive, es Cristo quien vive en mí.Y mi vida de ahora en la carne, la vivo en la fe del Hijo de Dios, que me amó y se entregó por mí". ${ }^{121}$ Consecuentemente, su ministerio lo concibe como un servicio por el cual la figura de Cristo llega a formarse en aquellos a quienes lleva el anuncio de la salvación: “hijos míos, por quienes vuelvo a sufrir dolores de parto, hasta que Cristo se forme en vosotros". ${ }^{122}$

Adquirir la forma de Cristo es, indisolublemente, formar parte de su cuerpo, la Iglesia. La formación está en función de una más viva comunión con Cristo y con la Iglesia, y de una participación cada vez más generosa en la vida y la misión de la comunidad cristiana. Es preciso tener este criterio en cuenta, frente a las tentaciones de una falsa formación que, acaso a través de sofisticadas reflexiones o normas distintivas, sirvan para desviar a la persona de la comunidad cristiana (gnosticismo, pelagianismo). ${ }^{123}$ Estas manifestaciones, de las que ya Jesús advertía a fariseos y escribas, corren en sentido contrario al impulso del Espíritu, que siempre actúa para la continua renovación y el crecimiento de la comunión eclesial, sosteniendo una misión capaz de llegar a todos. ${ }^{124}$

En definitiva, la meta de la formación cristiana se identifica con la alegría de ser santos, que se manifiesta en una vida personal y eclesial orientada por el espíritu de las bienaventuranzas y modelada por la compasión de Cristo hacia los pobres y sufrientes. ${ }^{125}$

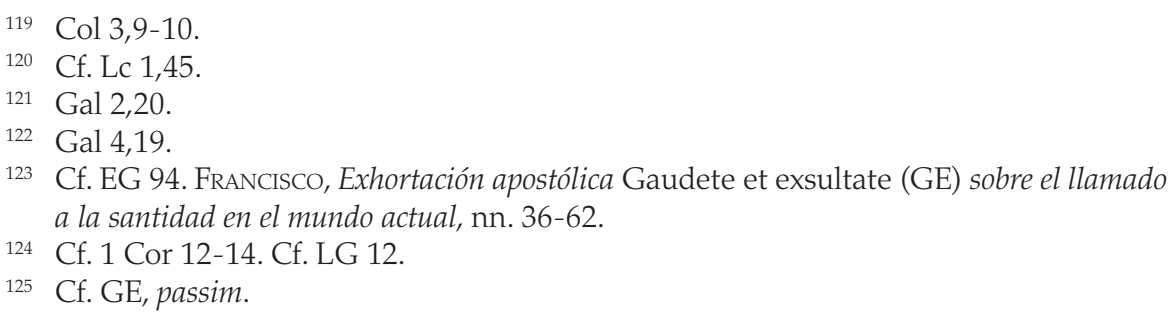




\subsection{Formación integral y permanente}

Dos cualidades destaca el papa Juan Pablo II en la formación de los creyentes: esta debe ser integral y permanente. ${ }^{126}$ Estas dos características nos proporcionan un buen criterio para evaluar la calidad de nuestros planteamientos concretos de formación.

En primer lugar, toda formación cristiana debe aspirar a ser integral. Acoger esta indicación es un buen antídoto contra las tendencias subjetivistas y relativistas típicas de nuestra cultura postmoderna: frente al simple desinterés o la ignorancia irresponsable, la fragmentación de conocimientos y el bricolage religioso, las simplificaciones y reduccionismos, el consumo gnosticista de experiencias, los vicios intelectualista o moralista, la incoherencia entre fe creída y fe vivida... Esta cualidad integral de la formación, que a nivel básico caracteriza a la catequesis de iniciación cristiana, ${ }^{127}$ se mantiene como fundamental en todas las etapas y circunstancias de la vida de los cristianos. Esto debe tenerse en cuenta en cada itinerario formativo, previendo acciones que fomenten cada una de las dimensiones de la vida cristiana - conocimiento de la fe, testimonio de una relación viva con el Señor, implicación en la vida y la misión de la comunidad cristiana, celebración de la Iglesia- ${ }^{128}$ De este modo, se manifiestan, por una parte, la unidad y la integridad de la $\mathrm{fe}^{129}$ y, por otra, la integridad de las dimensiones de la persona que quedan iluminadas y configuradas por la gracia. Es la persona entera la que ha de disponerse a crecer en su formación cristiana, en todas las dimensiones de su ser y en todos los ámbitos en los que desarrolla su existencia. Por ello, si bien un aspecto puede destacarse por algún centro de interés que motive inicialmente la formación, o por una vocación o dedicación especiales, una sola perspectiva no agota la totalidad de la propuesta de vida cristiana que cada persona está llamada a desplegar.

En segundo lugar, se destaca que la formación ha de ser permanente. Frente a la tentación de pensar que ya estamos formados, esta cualidad de la formación nos recuerda nuestra condición perenne de discípulos, en continuo seguimiento de nuestro Maestro. Supone, asimismo, la responsabilidad de la comunidad eclesial de establecer cauces para la continuidad y la estabilidad de los procesos de formación. Una de las situaciones que hay que ayudar a superar es la interrupción demasiado temprana de la catequesis, que no ofrece la oportunidad para una síntesis personal

\footnotetext{
126 Cf. CL 57.

127 Cf. DGC 67.

128 Cf. Hch 2,42.

129 Cf. Francisco, Carta encíclica Lumen fidei (LF) sobre la fe, nn. 47-49.
} 
de fe. Una gran masa de católicos vive pensando que ya recibieron una formación suficiente de pequeños y, en cambio, se encuentran desarmados ante la fuerte corriente de ideas y valores contrarios al evangelio que son dominantes en nuestra sociedad. En la práctica, se hallan colonizados por una cosmovisión incompatible con la buena noticia que un día recibieron y solo se acercan esporádicamente a la comunidad cristiana para solicitar la celebración de algún sacramento, con alguna ocasión familiar. Muchos otros, que participan habitualmente de distinto modo, tampoco se encuentran muy firmes, ni verdaderamente capacitados para ser fermento del Reino en los distintos ámbitos sociales. Por su parte, la Iglesia está obligada a contribuir a que las mentes y los corazones de todos puedan verse iluminados y fortalecidos por la alegría del evangelio, a través de una configuración decididamente cristiana y eclesial de su personalidad. Para ello, no podemos eludir la responsabilidad de establecer procesos formativos adaptados a edades y circunstancias, a través de cada una de las plataformas evangelizadoras.

\subsection{Formación para la misión}

A la hora de plantear un plan de formación cristiana, no debemos conformarnos con sostener una permanente minoría de edad de los fieles, sino que es preciso orientar decididamente nuestros esfuerzos y medios hacia la constitución en cada diócesis de "un laicado cristiano maduro". ${ }^{130}$ La madurez de la vida cristiana incluye la vivencia cada vez más plena de las bienaventuranzas, las obras propias del amor y la fuerza difusiva de la fe a través de una vida de testimonio y de la propuesta explícita del evangelio a los demás. En particular, no debemos olvidar la capacidad integradora de la misión, ya antes mencionada, que ha de impregnar la formación con el dinamismo propio de una fe comunicable por el testimonio de la vida, el diálogo y el anuncio. En definitiva, la formación cristiana tiene como fin la conformación del cristiano según la figura del "discípulo misionero", dispuesto a ser llamado y enviado con todo el Pueblo de Dios como uno de los "evangelizadores con espíritu", sin los cuales la misión de la Iglesia quedaría paralizada. ${ }^{131}$

Una formación para la misión exige una mirada lúcida sobre las realidades concretas de nuestro entorno social y cultural, así como la adquisición de criterios conformes con el evangelio, que nos ayuden a dar un testimonio coherente y nos permitan hacer un anuncio creíble a nuestros

\footnotetext{
130 AG 21.

131 Cf. EG 259-283.
} 
contemporáneos. El método de la revisión de vida, ampliamente reconocido y usado por la Iglesia, se presta a este tipo de formación orientada a la misión en el corazón del mundo. Los criterios operativos, que el magisterio ofrece abundantemente en su Doctrina Social, permiten situarse cristianamente - por ende, con actitud testimonial y evangelizadora- en todos los entornos: matrimonio y familia, cultura y educación, mundo del trabajo y de la economía, política, mundo del sufrimiento y la marginación...

\subsection{La clave del primer anuncio}

La diversidad en los itinerarios de formación cristiana posibles viene condicionada por la misma diversidad de recorridos biográficos de las personas. Nuestra responsabilidad como Iglesia es ofrecer oportunidades y medios para que todos, en la situación concreta en que se encuentren, puedan percibir la llamada a dejarse iluminar y guiar por la luz del evangelio de Jesucristo. Hay que caer en la cuenta de que ya no podemos seguir haciendo ingenuamente lo que hemos hecho siempre, que era muy válido para el contexto de cristiandad. En nuestro contexto social y cultural, que tiende a olvidar sus raíces y expresiones cristianas, no es tan habitual como en períodos anteriores un recorrido ininterrumpido de educación en la fe desde la infancia hasta la vida adulta, o al menos una cierta ósmosis con un entorno social profundamente impregnado de referencias y valores cristianos. Más bien hay que contemplar la concreta posibilidad de que, en distintas etapas vitales, la persona esté en disposición de acoger un testimonio creíble y un primer anuncio que le muevan a responder personalmente a la llamada del Señor por la fe.

Esto nos obliga a ir estableciendo un modo de ser Iglesia más atento a la acción propiamente misionera de la evangelización, distinguiéndola del resto de acciones evangelizadoras: catequético-iniciatoria y pastoral. Hay que advertir que estos "momentos esenciales" de la evangelización "no son etapas cerradas: se reiteran siempre que sea necesario, ya que tratan de dar el alimento evangélico más adecuado al crecimiento espiritual de cada persona o de la misma comunidad". ${ }^{132}$ Así pues, en cada etapa de edad y para cada circunstancia hay que prever los cauces y los instrumentos para un primer anuncio. De hecho, cada una de las realidades eclesiales debe estar muy atenta a esta tarea, sin la cual no podemos decir cumplido el mandato de Jesús de "ir al mundo entero y proclamar

132 DGC 49. 
el evangelio a toda la creación" ${ }^{133}$ Cada iniciativa eclesial debe preocuparse por hacer llegar a todos este mensaje:"Dios te ama, Cristo te salva, Él vive y derrama su Espíritu en tu vida como un manantial". ${ }^{134}$ Además, este primer anuncio o kerygma ha de entenderse como una clave continua, sin la cual la comunicación y la misma vivencia de la fe pierden su dinamismo vital y su capacidad de contagio a otros. ${ }^{135}$

\subsection{Itinerarios formativos}

La responsabilidad de la formación se concreta, a nivel eclesial, en la propuesta de itinerarios, que sirvan de cauce para la progresiva configuración de personalidades cristianas y de comunidades maduras, desbordantes con la vida del Espíritu y capaces de asumir con audacia el desafío de la misión. La propuesta de unos itinerarios formativos ordinarios expresa la responsabilidad de cada diócesis y por ello, sobre todo, se refiere a las parroquias, en cuanto "células de la Iglesia particular". ${ }^{136}$ Otras realidades eclesiales (colegios, asociaciones...) están también llamadas a colaborar en la formación cristiana ordinaria de muchos fieles. Los itinerarios ofrecidos por estas realidades han de ser, en cualquier caso, conocidos por el obispo, quien es en su diócesis"el moderador de todo el ministerio de la palabra" ${ }^{137}$ Nos referimos, primeramente, a los itinerarios formativos ordinarios. De entre ellos, nos detenemos en el modelo formativo de adultos. Seguidamente, trataremos los cauces complementarios y especializados.

\subsubsection{El modelo formativo de adultos}

Jesús, que decía "no impidáis a los niños acercarse a mí", 138 en cambio no dirigía su predicación principalmente a ellos, sino a personas capaces

\footnotetext{
133 Mc 16,15.

134 Cf. Francisco, Exhortación apostólica postsinodal Christus vivit (CV) a los jóvenes y a todo el Pueblo de Dios (2019), nn. 111-133.

135 Cf. EG 164.

136 AA 10.

137 CIC, can. 756 §2; cf. 772 §1; 774 §1; 775 §1; 777. Esta labor de moderación propia del obispo se realiza tanto de forma directa, como a través de las vicarías y delegaciones (nivel diocesano), arciprestazgos y parroquias (nivel local). En particular, debe cuidarse el aspecto formativo en los estatutos (cf. CIC, can. 304 §1) y es necesario velar por que la formación de los fieles subraye la vocación propia del laicado, como evangelizadores en medio de la sociedad y como colaboradores de la pastoral orgánica de la Iglesia diocesana (cf. CIC, can. 327-329).

138 Mt 19,14 par.
} 
de escuchar con responsabilidad su mensaje y su propuesta de vida. Por ello, no es de extrañar que el Directorio General para la Catequesis se refiera a la catequesis de adultos como el modelo paradigmático de toda la transmisión de la fe: "Esto implica que la catequesis de las otras edades debe tenerla como punto de referencia, y articularse con ella en un proyecto catequético coherente de pastoral diocesana". ${ }^{139}$ La formación cristiana de adultos engloba las siguientes acciones:

\subsubsection{Iniciación Cristiana de adultos: el Catecumenado}

En particular, el Catecumenado de adultos constituye"el modelo de toda catequesis", que "ha de inspirar, en sus objetivos y en su dinamismo, a las otras formas de catequesis". ${ }^{140}$ Desde la restauración del Catecumenado en el Concilio Vaticano II, esta realidad va adquiriendo una frecuencia creciente entre nosotros, lo cual reclama una atención especial y la provisión de medios adecuados. ${ }^{141}$ El Catecumenado de adultos es un itinerario litúrgico, catequético y espiritual, que presupone la acción misionera de la Iglesia y un período previo de acercamiento y prueba (precatecumenado). En esa etapa, la comunidad cristiana media con su presencia y oración para que el Señor suscite en el corazón del candidato una incipiente acogida del evangelio y el deseo de ser incorporado a la Iglesia. Terminada esta fase, y realizado el ingreso en el orden de catecúmenos, comienza el itinerario propiamente catecumenal, de duración variable (de uno a varios años). Este itinerario debe reunir las características propias de toda catequesis: "formación orgánica y sistemática de la fe"; "básica, esencial, centrada en lo nuclear de la experiencia cristiana, en las certezas más básicas de la fe y en los valores evangélicos más fundamentales"; "una iniciación cristiana integral" que "incorpora a la

139 DGC 59. Acerca del desafío de la transmisión generacional de la fe, hay que afirmar la responsabilidad permanente que las familias y comunidades cristianas tienen de despertar la fe en los más pequeños y acompañar su crecimiento en el camino hacia la vida adulta. Esto implica distinguir, también para estas edades, las etapas misionera, catequética y pastoral. No hay espacio en estas páginas para tratar la transmisión de la fe a niños, adolescentes y jóvenes, con las acciones específicas que ello requiere: despertar religioso, iniciación cristiana, pastoral de infancia, adolescencia y juventud.

140 Ibid.

141 Cf. SC 64; Congregación Para el Culto Divino, Ritual de la Iniciación Cristiana de Adultos (RICA) (1972); ICRO 24-30; ConfERENCIA EPISCOPAL Española, Orientaciones pastorales para el catecumenado (2002); OBispos de las Diócesis del Sur de España, Renacidos del agua y del Espíritu. Instrucción pastoral sobre la Iniciación Cristiana, Madrid, BAC, 2013, 55-62; 145-160. 
comunidad que vive, celebra y testimonia la fe" ${ }^{142}$ Referencias imprescindibles en este proceso son el testimonio de la comunidad parroquial, la Palabra de Dios y el Catecismo de la Iglesia Católica. Las cuatro partes del Catecismo apuntan a la integralidad de dimensiones de la fe, así como a la "forma eclesial" de esta: ${ }^{143}$ la profesión de la fe, la celebración del misterio cristiano, la vida en Cristo y la oración cristiana.

\subsubsection{Iniciación Cristiana de adultos: Confirmación y Eucaristía}

Como parte de la Iniciación Cristiana hay que considerar también la preparación y la administración del sacramento de la confirmación a los adultos bautizados que no lo hayan recibido aún, así como el acceso a la participación plena en la eucaristía. Situaciones personales diversas justifican prever itinerarios de distinta duración: desde uno breve para aquellos adultos católicos que participan habitualmente de la vida y la celebración de la Iglesia, hasta uno más amplio para aquellos que requieran empezar a conocer y a vivir los aspectos principales de la fe cristiana. En cualquier caso, se debe velar por la calidad de este proceso, por el que las personas que lo solicitan completan su iniciación cristiana. Asimismo, considerando la clave del primer anuncio, debería evaluarse la necesidad de derivar a estas personas más bien hacia un proceso de carácter precatecumenal, que consideramos a continuación.

\subsubsection{Propuesta de fe}

Cada vez es más frecuente encontrar a personas que se acercan a la Iglesia con motivo de alguna celebración familiar, pero que no participan habitualmente de la vida de la comunidad cristiana, ni han realizado una síntesis vital de fe, a pesar de haber recibido alguna catequesis durante su infancia. Entre ellos también son muchos quienes no han concluido su iniciación cristiana y solicitan el sacramento de la confirmación. De forma más general, hay que considerar la masa cada vez más amplia de personas que viven sumergidas en la cultura del indiferentismo religioso y no cuentan con referencia trascendente alguna. Esto hace frecuente que se acerquen a nuestras comunidades laicos adultos con escasa experiencia eclesial, pero que, si se les ofrece, se muestran dispuestos a

142 DGC 67-68. Cf. JuAn PAblo II, Exhortación apostólica Catechesi tradendae sobre la catequesis en nuestro tiempo, AAS 71 (1979) 1277-1340, nn. 18-25. Cf. SubComisión ePISCOPAL DE CATEQuesis, Encuentro con Jesús, el Cristo. Itinerarios para los catecúmenos, Madrid, Edice, 2017.

143 Cf. LF 22. 
escuchar de nuevo el anuncio cristiano como buena noticia para sus vidas. Debemos estar preparados para hacerles una propuesta renovada de la fe e integrarlos en la vida comunitaria.

Es responsabilidad de la comunidad cristiana, y de cada uno de sus miembros, aprovechar todas las ocasiones posibles para hacer una propuesta alegre, coherente y creíble de la fe. Estas ocasiones se presentan, sobre todo, en las situaciones personales o familiares de especial fragilidad o de especial gozo, allí donde la existencia se abre a la pregunta por su sentido y al misterio del don que la sostiene: el sufrimiento ante la enfermedad o la muerte de un ser querido, la esperanza por un proyecto matrimonial, el nacimiento de un hijo, los éxitos o los fracasos compartidos... Muchas familias siguen acudiendo a solicitar sacramentos, una educación cristiana para sus hijos en edad catequética... Esto nos da una oportunidad preciosa de anunciar la fe, en clave de primer anuncio, sabiendo que el evangelio es hoy una total novedad para muchos. Sin embargo, en un contexto de demandas religiosas decrecientes, no basta esperar a que acudan a la Iglesia; cada vez se hace más urgente la llamada a salir, para realizar una siembra más generosa y audaz del kerygma, "saliendo a los cruces de los caminos" para convocar a todos. ${ }^{144}$ En estos momentos, debemos aprender a remar mar adentro y echar allí las redes con verdadera intención de pescar. ${ }^{145}$

De la sensibilidad ante esta urgencia, han surgido diversas iniciativas en forma de instrumentos y métodos de primer anuncio. En todo caso, de forma organizada y sistemática, la propuesta de la fe a adultos es algo que debe realizar cada una de las plataformas eclesiales. Es imprescindible buscar medios con los que despertar en la gente el "anhelo de infinito" que, sin duda, albergan en el fondo de sus corazones. ${ }^{146}$ Se hace imprescindible responder a la realidad de muchos que, habiendo pasado la edad habitual de la catequesis, se acercan con deseo, acaso tímido, de escuchar al Señor y de seguir sus pasos, reviviendo en sus vidas la experiencia misma de los primeros discípulos: "Maestro, ¿dónde vives?" ${ }^{147}$ Es responsabilidad de la comunidad cristiana y de cada realidad eclesial acompañar este impulso del Espíritu hasta la plena acogida de Jesucristo y de su mensaje, hasta la plena participación en la vida de la Iglesia y en su misión.

\footnotetext{
144 1Cf. EG 19-49. Cf. Lc 14,23

1451 Cf. Lc $5,4$.

146 1Cf. EG 169. Este enfoque reclama una antropología de fondo, capaz de sostener el camino posible hacia la fe y su propuesta razonable. Cf. Francisco CASTRO PÉrez, Luz de los hombres. Fundamentos de antropología pastoral, Santander, Sal Terrae, 2020.

147 IJn $1,38$.
} 


\subsubsection{Equipos de vida}

Es muy recomendable que todos los laicos adultos que deseen profundizar en la fe e insertarse en la vida y la misión de la Iglesia, a través de un proceso de formación integral y permanente, participen en el modo formativo de los equipos de vida. Conviene distinguir esto de la formación que se desarrolla en los equipos de servicio, dedicados a diversas tareas de la evangelización (catequesis, caridad, liturgia...). A diferencia de esta formación específica para el servicio y la evangelización, los equipos de vida forman parte de los procesos formativos ordinarios, destinados a una formación cristiana integral. Los acompañantes de estos equipos, en nombre de toda la comunidad y bajo la supervisión de los pastores, tienen la delicada labor de guiarlos en su crecimiento hacia Cristo en todas las dimensiones de su vida: espiritual, personal y familiar, comunitaria y apostólica. Se ha de poner especial cuidado en que el equipo ayude a sus miembros a una unidad de vida cada vez mayor, fundada en la unión con Cristo: ${ }^{148}$

La formación de los laicos ha de contribuir a vivir en la unidad dimensiones que, siendo distintas, tienden con frecuencia a escindirse: vocación a la santidad y misión de santificar el mundo; ser miembro de la comunidad eclesial y ciudadano de la sociedad civil; condición eclesial e índole secular en la unidad de la novedad cristiana; solidario con los hombres y testigo del Dios vivo; servidor y libre; comprometido en la liberación de los hombres y contemplativo; empeñado en la renovación de la humanidad y en la propia conversión personal; vivir en el mundo, sin ser del mundo (Jn 17,11.14-19), como el alma en el cuerpo, así los cristianos en el mundo. ${ }^{149}$

Para este fin, la formación no puede quedarse en la asimilación de nociones, sino que debe estar estrechamente ligada con la vida concreta de los que participan en el proceso, ser una formación en la acción: que abra la mirada al mundo según la luz del evangelio y aporte criterios para vivir según un auténtico espíritu cristiano. El método de revisión de vida, orientado precisamente a esta formación activa, está avalado por la enseñanza y la experiencia de la Iglesia. ${ }^{150}$ En cuanto al modo concreto en que pueda plasmarse una vida testimonial en medio de la sociedad, ha de ponerse especial atención en el estudio de la Doctrina Social de la

\footnotetext{
148 Cf. AA 4.

149 Conferencia Episcopal Española, Los cristianos laicos, Iglesia en el mundo. Líneas para promover la corresponsabilidad y participación de los laicos en la vida de la Iglesia y en la sociedad civil (CLIM) (1991), n. 77. Cf. LG 38; Carta a Diogneto, 6 (PG 2, 1175); EN 76; CL 15; 58-59.

150 Cf. AA 29.
} 
Iglesia, en cuyo acervo se hallan "los principios de reflexión, los criterios de juicio y las directrices de acción" capaces de orientar a los laicos en su vocación propia. ${ }^{151}$

La propuesta de fe a adultos, que tratamos anteriormente, puede considerarse una etapa de convocatoria, que, para todos los que deseen seguir profundizando en la fe junto a otros, está llamada a prolongarse en sucesivas etapas de crecimiento de su identidad cristiana. ${ }^{152}$ La fase de iniciación es el tiempo en que se constituye el equipo de vida, donde la persona empieza a ser acompañada personal y grupalmente en su responsabilidad de crecer en la fe. Un medio muy adecuado para ello es la elaboración, hacia el final de esta etapa, de un proyecto personal de vida cristiana, que se pueda contrastar a nivel grupal y también personal con el acompañante o con un sacerdote. En la etapa de consolidación, el grupo de fe ya lleva recorrido un camino de confianza entre sus miembros y de cierta estabilidad en el proceso formativo. Esto debe manifestarse en la paulatina integración vital de los medios que la Iglesia ofrece a la persona para una plena vivencia de la fe: escucha de la Palabra, oración personal y comunitaria, sacramentos, incorporación efectiva a la vida y la misión de la comunidad cristiana. La etapa de maduración permanente es la de aquellos laicos adultos que, consolidado su proceso de profundización y crecimiento en la fe, desean responder toda su vida a la llamada que el Señor les hace, personal y en comunidad, a la santidad laical, la plena madurez cristiana y evangelizadora. ${ }^{153}$

El itinerario de formación debe ser complementado, según la situación personal de los miembros y la idiosincrasia del mismo grupo, con todo lo que pueda contribuir a su proceso formativo: documentos magisteriales recientes u otros fundamentales, formación bíblica, espiritual, temas de vida conyugal y familiar... La formación integral y permanente se despliega así con toda su potencialidad, hasta hacer de quienes participan en ella evangelizadores con Espíritu, verdaderos pilares de la vida de la comunidad cristiana y de su misión en el corazón del mundo. Se trata de los cristianos laicos bien formados que nuestra Iglesia y nuestra sociedad necesitan.

La conveniencia de promover este espacio de formación cristiana viene dada por la misma responsabilidad de desplegar todo el potencial de la fe, tanto por parte de cada fiel como por parte de los pastores. Que

151 Pontificio Consejo "Justicia y Paz", Compendio de la Doctrina Social de la Iglesia, 7.

152 Cf. Comisión Episcopal de Apostolado Seglar, Proyecto de Acción Católica General, Madrid, Edice, 2014, III.5.2.

153 Puede ser un buen hilo conductor para esta etapa de formación desde la vida y para la vida Comisión Episcopal de Apostolado Seglar, Itinerario de Formación Cristiana para Adultos. Ser cristianos en el corazón del mundo, 8 vol., Madrid, Edice, 2008-2020. 
ello, además, se realice en formas diversas de asociación, responde a la necesidad de continuidad y estabilidad del proceso formativo, de la misma vida y misión de las comunidades, así como de una mayor eficacia evangelizadora. La responsabilidad de la Iglesia a este respecto se concreta en el proyecto de la Acción Católica, que "no es una asociación más", sino "la forma habitual apostólica de «los laicos de la diócesis», como organismo que articula a los laicos de forma estable y asociada en el dinamismo de la pastoral diocesana". ${ }^{154}$ En lo que respecta a la formación, la Acción Católica General está llamada a articular en cada parroquia y coordinar en la diócesis la formación de un laicado adulto consciente y responsable de su misión en la Iglesia y en medio de la sociedad. Cada parroquia es responsable del establecimiento de este proceso formativo ordinario en equipos de vida.

En lo que concierne a las diversas agregaciones eclesiales de origen fundacional, la formación en equipos de vida debe seguir lo que establezcan sus estatutos, si así lo prevén. Los itinerarios, sin descuidar los aspectos generales necesarios para una formación integral, deben adecuarse al fin apostólico concreto para el cual existe la asociación. Tanto los estatutos como los itinerarios deberían estar aprobados por la autoridad eclesiástica competente y ser conocidos por el Ordinario. El fomento y la coordinación diocesana de la formación en este ámbito forman parte del servicio que se espera de las delegaciones dedicadas a los laicos en cada diócesis, las cuales deben también animar la integración de los fieles que participan de estos procesos en la vida de sus parroquias y la contribución de todos a la pastoral orgánica diocesana.

\subsubsection{Itinerarios y cauces complementarios y especializados}

Además de los itinerarios formativos ordinarios, es imprescindible contar con otros itinerarios complementarios y especializados que, de forma transversal, salgan al paso de las necesidades especiales de formación cristiana en situaciones vitales diversas y también de la formación de los evangelizadores en todos los campos del apostolado. Diocesanamente, esta responsabilidad se expresa en las iniciativas que desde las distintas delegaciones e instancias diocesanas se propongan de forma esporádica, periódica o estable, con itinerarios y materiales adecuados que aseguren la preparación de los agentes y la coordinación con cualesquiera otras iniciativas eclesiales relativas a su campo de apostolado.

154 CLIM 95. El Concilio Vaticano II se refiere a la Acción Católica de forma explícita en CD 17, AA 20 y AG 15. En Christifideles laici, es la única asociación que Juan Pablo II nombra (CL 31). 


\subsubsection{Instrumentos y métodos de primer anuncio}

Como quedó dicho en el apartado anterior, prácticamente todas las realidades diocesanas deben contar entre sus prioridades la propuesta de la fe como tarea irrenunciable. La audacia en la misión es hoy una urgencia que nadie en la Iglesia debe rehuir. Una contribución providencial a esta misión la desarrollan diversas iniciativas, llamadas instrumentos o métodos de primer anuncio. A través de estos medios, se convoca a personas alejadas de la fe aprovechando diversos centros de interés, para intentar hacer llegar de forma incisiva a sus corazones el mensaje de la salvación en sus circunstancias concretas: jóvenes, personas que se abren a la cuestión del sentido de sus vidas, matrimonios, piedad popular... Al utilizar estas iniciativas, se debe evitar que su servicio destinado a personas que aún no han tenido un encuentro personal con Cristo, y que conviene distinguir de las asociaciones debidamente aprobadas por la autoridad eclesiástica- se contamine de la pretensión proselitista de generar innecesariamente nuevas agregaciones de fieles. Esto debilitaría a la comunidad cristiana y dispersaría las fuerzas disponibles para la evangelización. ${ }^{155}$ Más bien, según su propia condición de meros métodos o instrumentos, deben acompañar a las personas que, a través de sus actividades, descubren la riqueza de la fe para que puedan incorporarse cuanto antes a la vida ordinaria de la comunidad cristiana en sus parroquias.

\subsubsection{Lineas transversales de formación}

Hay cuestiones que, por su importancia, requieren ser tratadas asiduamente, no solo como un tema aislado, sino constituyendo una línea formativa transversal en los distintos itinerarios formativos ordinarios, de los cuales no pueden faltar. Es el caso, durante la adolescencia y la juventud, de una imprescindible educación afectiva y sexual, ${ }^{156}$ una paulatina formación para la misión en la Iglesia y en medio de la sociedad, ${ }^{157}$ un discernimiento vocacional orientado por los valores evangélicos ${ }^{158}$ y una necesaria preparación remota al matrimonio y la vida familiar. ${ }^{159}$ Las delegaciones diocesanas de infancia y juventud, pastoral vocacional y pastoral

\footnotetext{
155 Cf. AA 19; IE 7 y 10.

156 Cf. Francisco, Exhortación apostólica postsinodal Amoris laetitia (AL) sobre el amor en la familia, AAS 108 (2016) 311-446, nn. 280-286.

157 Cf. EG; CV 175-178.

158 Cf. CV 248-298.

159 Cf. AL 205; CV 249-267.
} 
familiar tienen la responsabilidad de contribuir, coordinadamente, a que estas cuestiones formen parte habitual de los procesos ordinarios de formación, a través de encuentros, charlas, materiales y otros medios. Lo mismo ocurre en el caso de los equipos de vida adultos, en los que es imprescindible mantener una formación y una atención permanentes a algunas cuestiones doctrinales y morales que conciernen directamente a la espiritualidad laical: vida conyugal y familiar, presencia y testimonio en los diversos ambientes e instituciones sociales, moral social en sus diversos ámbitos... El estudio asiduo y profundo de la Doctrina Social de la Iglesia, con sus concreciones para cada situación, debe ser fomentado por la delegación para los laicos, sobre todo en los ámbitos cultural y sociopolítico. En lo que concierne al campo del matrimonio cristiano, para ayudar a los esposos a vivir en plenitud su vocación conyugal y familiar, los itinerarios de formación pueden verse enriquecidos por ayudas específicas de la pastoral familiar.

\subsubsection{Formación específica para circunstancias diversas}

Hay una variedad inabarcable de situaciones que, a lo largo de la vida de las personas y las familias, en los diversos ambientes y colectivos humanos, en cada comunidad cristiana..., exigen de la Iglesia una respuesta también en el campo formativo. En esto queda especialmente manifiesta la necesidad de coordinar las diversas instancias diocesanas y las demás iniciativas llamadas a contribuir en la evangelización.

Una circunstancia especial la constituye el cambio de situación de los jóvenes cuando abandonan el nido y empiezan un período de estudio fuera de su domicilio habitual, o cuando comienza su incorporación al mundo laboral. A menudo, estas nuevas situaciones implican un corte definitivo en el proceso de formación cristiana. Es responsabilidad de la Iglesia salir al paso de esta circunstancia, ofreciendo espacios acogedores, que respondan con realismo y flexibilidad a las necesidades de jóvenes que salen de sus ambientes de origen, que vienen de lejos por motivos de estudio, o que empiezan a sufrir las durezas de la vida laboral. Las comunidades han de estar atentas a estas situaciones personales y acompañarlas discretamente, para animar a sus jóvenes a vivir la fe allí donde se encuentren. Por su parte, las diversas plataformas evangelizadoras tienen aquí un precioso campo que cultivar.

Entre los cambios de situación en la etapa juvenil, que también supone con frecuencia el abandono de la formación cristiana, está el comienzo de relaciones afectivas de pareja que, ineludiblemente, se da en esta etapa liminar hacia la vida adulta. Evitar en este caso el abandono 
supone anticipar la llegada de estos cambios e incidir convenientemente, de forma transversal y también sistemática, en los contenidos afectivos y sexuales de la formación, que ayuden a los jóvenes a descubrir la llamada al amor encerrada en sus nuevas vivencias. Además, en el proceso de elección vocacional, motivada por el ideal cristiano de la entrega personal, se requiere una preparación específica para los distintos estados de vida cristiana. En concreto, el sacramento del matrimonio exige un especial cuidado en su preparación próxima e inmediata, a través del acompañamiento de la comunidad y de catequesis suficientemente prolongadas, en las que se tenga en cuenta la situación personal y de fe de las parejas. ${ }^{160}$

La celebración del bautismo de los hijos ofrece también una preciosa ocasión de encuentro con las familias y de acompañamiento en su proceso de crecimiento creyente. ${ }^{161}$ Sucesivamente, puede haber diversas iniciativas de escuelas de padres o de catequesis familiar, que ayuden a los padres en su tarea educativa y les permitan también acompañar el proceso catequético de sus hijos. ${ }^{162}$ Las delegaciones de catequesis pueden ofrecer orientación y ayuda al respecto, ante la variedad de situaciones que puedan presentarse. Baste mencionar la realidad tan frecuente de niños con necesidades educativas especiales.

Otras situaciones delicadas y de especial fragilidad necesitan un acompañamiento y una oferta especializados, que exigen a menudo la ayuda de personas con capacitación profesional: matrimonios en dificultad, situaciones diversas de sufrimiento y duelo... La comunidad cristiana debe contar también con personas capacitadas para atender estas realidades y brindar recursos a quienes las padecen. ${ }^{163}$ Las delegaciones de pastoral de la salud y Cáritas, cada una en su campo, suelen ofrecer formación en el terreno de la relación de ayuda. Por su parte, los tribunales eclesiásticos, las delegaciones de pastoral familiar y centros de orientación familiar ofrecen también orientación y medios. En lo que concierne a la formación cristiana de los fieles que atraviesan estas situaciones dolorosas, es imprescindible que la comunidad cristiana aprenda a"acompañar, discernir e integrar la fragilidad". ${ }^{164}$

Aunque es responsabilidad de todos los fieles llegar a tener un conocimiento suficiente de las enseñanzas sociales de la Iglesia, esto se hace

\footnotetext{
160 Cf. AL 205-216; Conferencia Episcopal Española, Directorio de pastoral familiar (2003), nn. 95-127.

161 Cf. Ritual del Bautismo de niños (1970), nn. 10-32; 54-60; 87-103; ICRO 76-78.

162 Cf. ICRO 34; Renovar la catequesis de infancia, 40.

163 Cf. Juan Pablo II, Carta apostólica Salvifici doloris sobre el sentido cristiano del sufrimiento humano, AAS 76 (1984) 201-250; n. 29; AL 204; 231-258.

164 AL 291-312.
} 
una necesidad concreta y urgente para los profesionales cristianos, cada uno en su ámbito. Más allá del fomento general de la Doctrina Social de la Iglesia, esta debe ser difundida de manera más concreta y profunda en sus campos por diversas instancias diocesanas: Cáritas, delegación de medios de comunicación, de enseñanza, pastoral universitaria, familiar, de la salud...

\subsubsection{Formación de agentes de pastoral y formación teológica}

Un capítulo aparte merecen los esfuerzos que es preciso desplegar para la formación de formadores y, en general, de todos los agentes de pastoral. ${ }^{165}$ En cada diócesis suele haber una abundante oferta de cursos de capacitación básica, jornadas formativas, ciclos de charlas, muy útiles para quienes necesiten formarse en cada uno de los campos del apostolado. Conviene tenerlo presente para saber aprovecharlo bien, y contar con la ayuda de las distintas delegaciones para las demandas formativas que puedan surgir.

A toda esta lista de posibilidades, hay que añadir la posibilidad de formación teológica, que muchas diócesis ponen al alcance de sus fieles, o que estos pueden adquirir por diversas vías. Puede tratarse también de una formación no académica, orientada especialmente a la capacitación de agentes de pastoral, de marcado carácter vital y práctico. La formación de los laicos en este terreno es muy recomendada por la Iglesia, ${ }^{166}$ y se hace imprescindible para todos los que deseen entrar en diálogo profundo y propositivo con la cultura de nuestro tiempo, en el nuevo contexto de la misión eclesial. ${ }^{167}$ Se hace entonces necesario adentrarse en los misterios de la fe con la ayuda de la filosofía, "indispensable para profundizar la inteligencia de la fe y comunicar la verdad del evangelio a cuantos aún no la conocen". ${ }^{168}$ De este modo nos capacitamos para"dar explicación a todo el que nos pida una razón de nuestra esperanza". ${ }^{169}$

\section{CONCLUSIÓN}

Al finalizar el recorrido que nos propusimos, comprobamos de nuevo la imbricación mutua de los aspectos de la misión, la comunión y la formación. En estas páginas hemos abordado esa relación mutua siguiendo

\footnotetext{
165 Cf. CLIM 75.

166 Cf. AA 32; CLIM 75; 85-86.

167 Cf. Francisco, Constitución apostólica Veritatis gaudium, AAS 110 (2018) 1-34, nn. 1-6.

168 JuAn Pablo II, Encíclica Fides et ratio sobre las relaciones entre fe y razón, AAS 91 (1999) 5-88, n. 67.

1691 Pe 3,15.
} 
el hilo de la misión, pues se trataba de la revitalización del apostolado seglar. Pienso que ha quedado suficientemente argumentado que esta misión no puede aspirar a ser fecunda sin la referencia constante a la comunión y a la formación. Estas otras dimensiones, por su parte, deben tener una orientación decididamente misionera, lo cual se hace patente en nuestro tiempo con particular urgencia.

Reconociendo esta urgencia de la misión, no he podido evitar un subrayado especial en el tema de la comunión. Estimo que se trata de un acento que hoy no debe faltar, precisamente en favor de la misión en su aspecto de mistagogía (el desde-dónde, el cómo y el hacia-dónde de la misión), consciente de que habitualmente está siendo objeto de olvido en planteamientos pastorales excesivamente centrados en el qué (el quehacer evangelizador) y trabajosamente ocupados también en el quién (formación). Esto se está revelando, a mi entender, como una peligrosa grieta en la barca eclesial donde todos somos convocados a remar, después de un largo experimento de decenios que no siempre ha mostrado los frutos que cabría esperar para la vida de las comunidades y para su fecundidad evangelizadora. Con ello siento justificado un cierto desequilibrio en el contenido de este estudio, que surge como reflexión acerca de la oportunidad de un Congreso "de laicos" donde, al querer dar voz a las múltiples iniciativas asociadas, quizá se ha postergado a la mayoritaria realidad laical, llamada a desarrollar su vida y su misión en el seno de las comunidades parroquiales $y$, desde ellas, en la concreta realidad social.

Finalmente, en el orden de la acción pastoral, el reto del laicado se nos revela como reto global de la Iglesia; así como, en el orden de la reflexión, la elaboración de una teología del laicado exigió durante el siglo pasado la transformación y el desarrollo global de toda la eclesiología. Espero que las ideas aquí expuestas puedan ofrecer alguna luz o, en cualquier caso, inspirar un diálogo que sirva para orientarnos en el inmenso desafío que tenemos planteado de ser Pueblo de Dios en salida. 